\title{
THE EARLY STAGES OF WEST AFRICAN MOSQUITOS.-VI.
}

\author{
By J. W. S. Macfie and A. Ingram, \\ West African Medical Service.
}

In this paper are described the early stages of a few more West African mosquitos. All the specimens were collected in the Gold Coast, and most of them at Accra or in the neighbourhood of that town. In drawing up descriptions of larvae we have followed the usual plan, but in the case of the setae on the head have given, when necessary, the terms employed by W. D. Lang in his admirable handbook of British Mosquitos. In drawing up descriptions of pupae we have used the terms (and lettering) suggested by one of us in his account of the chaetotaxy of the pupa of Stegomyia fasciata (Aëdes argenteus).* We have once more to express our indebtedness to Dr. G. A. K. Marshall, of the Imperial Bureau of Entomology, and to Mr. F. W. Edwards, of the British Museum, for help and advice and for the identification of species, and to Mr. A. J. Engel Terzi for his skilful execution of the figures.

\section{Anopheles nili, Theo.}

LARVA.-The larva of this mosquito has not yet been identified.

PuPA.-The pupa is rather small, length about $4 \mathrm{~mm}$. when extended, and not very highly chitinised. Two specimens were examined.

Cephalothorax. The respiratory trumpets resemble those of A. rufipes.

Abdomen (fig. 1). The paddles, which are about $0.65 \mathrm{~mm}$. long, are rather narrow, especially at their bases, the ratio of length to greatest breadth being about 1.9 to 1 . The midrib is very feebly developed, almost absent indeed, and the external buttress is ill-defined but appears to extend beyond the middle of the paddles. At the distal end are the usual two hairs, the proximal one small, straight, single or double, and the terminal one large, stout, shaped like a boot-hook. The fringe is rather long and very delicate, and extends round almost the whole paddle except only for a short distance on each side at the base.

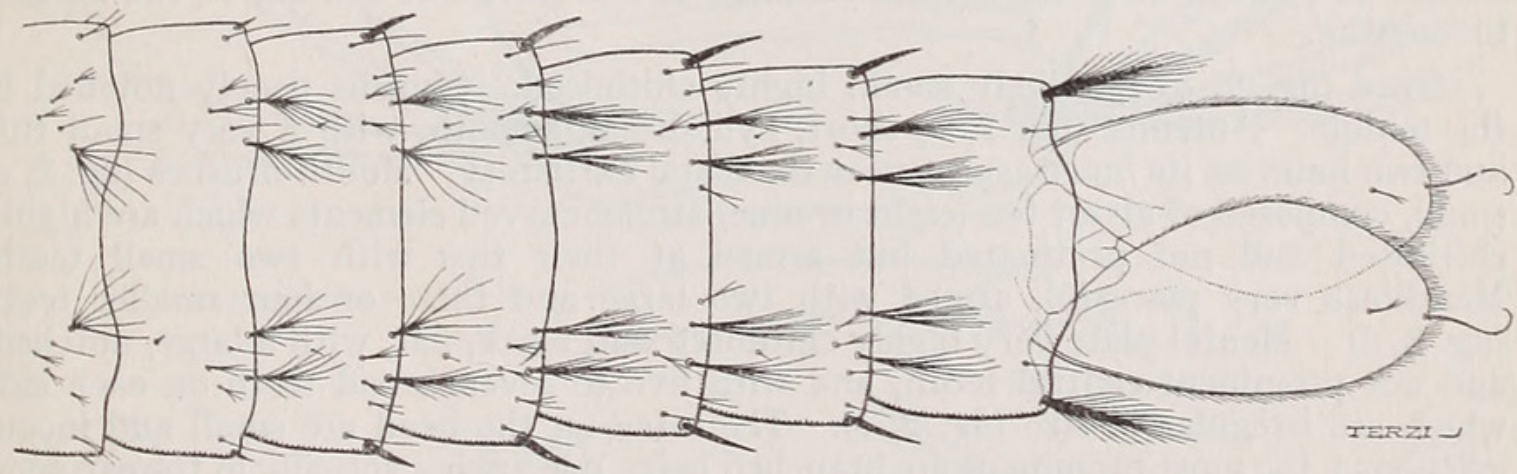

Fig. 1. Anopheles nili, Theo., abdomen of pupa, dorsal view.

The lateral setae (A) at the posterior angles of the abdominal segments are similar to those of $A$. funestus, and are very highly chitinised on the fourth to the eight segments. On segment viii they are long stout setae, about one quarter the length of the paddles, which give off numerous branches on each side ; on segments $\mathrm{v}$, vi, and vii they are moderately long, strong, slightly curved setae, with sharp

* Bull. Ent. Res. x, p. 164 . 
points; on segment iv they are smaller but still of considerable size, strong and sharply pointed; but on segments ii and iii they are minute, sharply pointed setae, and rather feebly chitinised. The sublateral (B) and submedian (C) setae on the dorsal aspect of the abdomen are unusually well developed, and on segments iii to vii they are large tufts. The sublateral setae resemble the lateral setae on segment viii, that is, they have a central stem which gives off numerous branches on each side; the submedian setae are more like ordinary branched setae. The dendritic tufts on segment $i$ are large and composed of long, fine hairs. The other setae of the pupa do not appear to call for special mention.

Diagnosis.-The pupa of $A$. nili somewhat resembles that of $A$. funestus, from which, however, it may be distinguished by having the submedian setae on segments $\mathrm{v}$ to vii developed as tufts instead of being long single or double hairs, as well as by other characters.

Habitat.-Oblogo, 7.ii.1921, larvae collected among plants of the water lettuce (Pistia stratiotes) in the river Densu.

\section{Megarhinus (Toxorhynchites) brevipalpis, Theo.}

A figure showing the paddles and the last three abdominal segments of the pupa of this mosquito has been published, together with a few words of explanation, by Bacot (Yellow Fever Commission, West Africa, Reports, iii, p. 145); and a larva, presumed to be that of $M$. brevipalpis, has been briefly described by Edwards (Bull. Ent. Res. iii, p. 375). Neither of these authors, however, has given sufficient details to distinguish the species, and indeed it seems not unlikely that the characters mentioned by them are mainly generic. As we have in our possession specimens of both larvae and pupae of $M$. brevipalpis, we have taken the opportunity of examining them in detail.

LARvA.- The larva when fully grown is very large, about $14 \mathrm{~mm}$. long, and dark grey or reddish-brown coloured, corresponding in tint to that of the debris at the bottom of the water in which it is found. In the laboratory, when under observation, we have fed it on larvae of Aëdes argenteus (Stegomyia fasciata). When at the surface of the water the attitude of the larva is less horizontal than that of Lutzia tigripes. If disturbed the larva at once seeks the bottom of the jar in which it is confined and is able to remain there for several minutes at least without coming to the surface to breathe.

Head (fig. 2, a) relatively small, highly chitinised. Clypeus deeply notched in the middle. Antenna (fig. 2, $b$ ) short, cylindrical, smooth, with a very small tuft and two hairs on its inner aspect near the distal extremity. Mouth-brushes (fig. 2, c) small, composed of about ten (eight or nine) strong curved elements which are highly chitinised and not pectinated but armed at their tips with two small teeth. Mandibles very powerful, armed with two large and three or four smaller teeth (fig. 2, d). Mental plate very highly chitinised and black, flat, with a large, notched, and not prominent central tooth, and with five to seven broad teeth on each side which are irregular in size (fig. $2, e$ ). The setae on the head are small and inconspicuous ; the most prominent are branched hairs, one arising actually in the eye spot, one above it, and two immediately in front of it ; a short row of four setae, a small tuft internally and three single hairs externally, on each side of the dorsum laterally and almost on a level with the bases of the antennae; and three single hairs on each side of the clypeus. Ventrally there is on each side a small tuft a little posterior to the root of the mandible and one or two other small hairs.

Thorax. Median setae rudimentary, lateral short and stout. The plumose, or more correctly serrated, hairs are short and thick with relatively stout barbs; some of them are branched. All the setae, except the most minute ones, arise from chitinous plates. 
Abdomen. There are serrated hairs arising from chitinous plates on every segment. Some of these hairs are relatively stout, slightly curved, and barbed only on their convex side (fig. $2, f$ ). On segment viii there is a single large chitinous plate on each side, from the posterior margin of which arise two stout, curved, serrated setae. There is no comb. The siphonal and subsiphonal setae appear to be absent ; the anal seta is a small single hair. The siphon is short, about twice as long as the diameter of its basal ring, and highly chitinised. There is no pecten. Near the base of the siphon, on each side, is a large tuft of three to five plumose hairs. The anal segment is slightly shorter than the siphon, completely chitinised ; its posterior

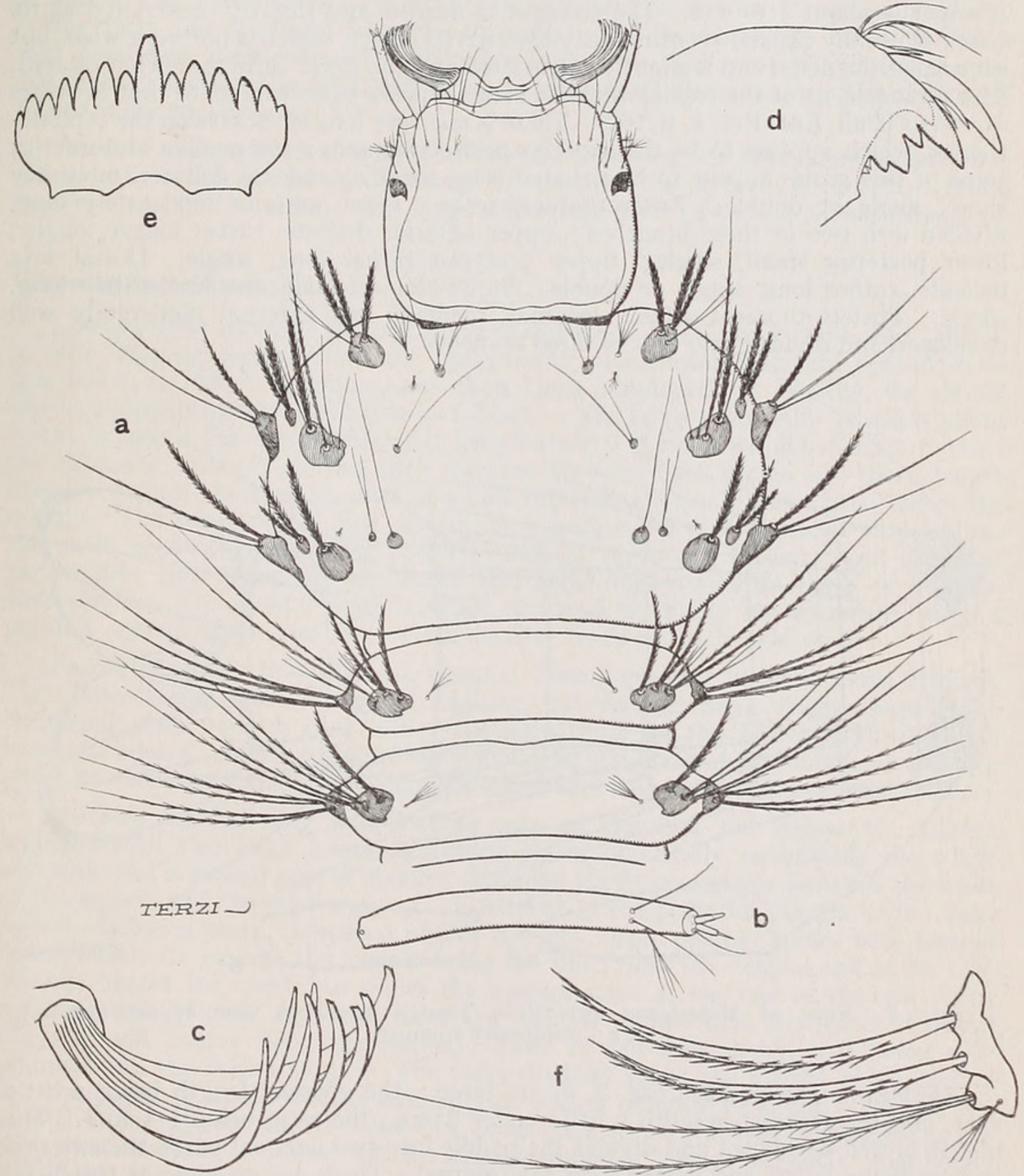

Fig. 2. Larva of Megarhinus (Toxorhynchites) brevipalpis, Theo. : a, anterior portion of body; $b$, antenna; $c$, mouth-brush; $d$, mandible; $e$, mental plate ; $f$, plumose hairs of abdomen 
border is fringed with long and short spines, and bears in the middle of each lateral margin a single stout serrated seta. The beard is well developed, composed of about ten pairs of branching hairs. The dorsal hairs on the posterior edge of the anal segment are long, four to six above and three or four below on each side. The anal papillae are very short and rounded, the dorsal pair being slightly the larger.

PUPA.-The pupa is very large, measuring about $14 \mathrm{~mm}$. when extended, highly chitinised, and dark-coloured. The duration of the pupal stage is about five days.

Cephalothorax. The respiratory trumpets (fig. $3, b$ ) are about $1 \mathrm{~mm}$. to $1 \cdot 2 \mathrm{~mm}$. long ; the ratio of the length of the closed portion (meatus) to the total length of the trumpet is about 1 to $1 \cdot 3$. The trumpet is narrow and slightly constricted at its base ; it usually expands continuously towards its orifice, which is not very wide, but sometimes the distal end is slightly constricted and the lower third somewhat dilated. The arrangement of the cephalothoracic setae appears to be similar to that in Aëdes argenteus (Bull. Ent. Res. x, p. 162). There is one very long stout seta on the cephalothorax, which appears to be the superior post-ocular seta; the median and inferior setae of this group appear to be situated close together and are delicate, relatively short, single or double. Anterothoracic setae: lower anterior moderately long, divided into two or three branches; upper anterior delicate, rather longer, single ; lower posterior small, single; upper posterior rather long, single. Dorsal seta delicate, rather long, single or double. Supra-alar seta delicate, moderately long, single. Postero-thoracic setae: internal, median, and external moderately well developed and divided into two or three branches.

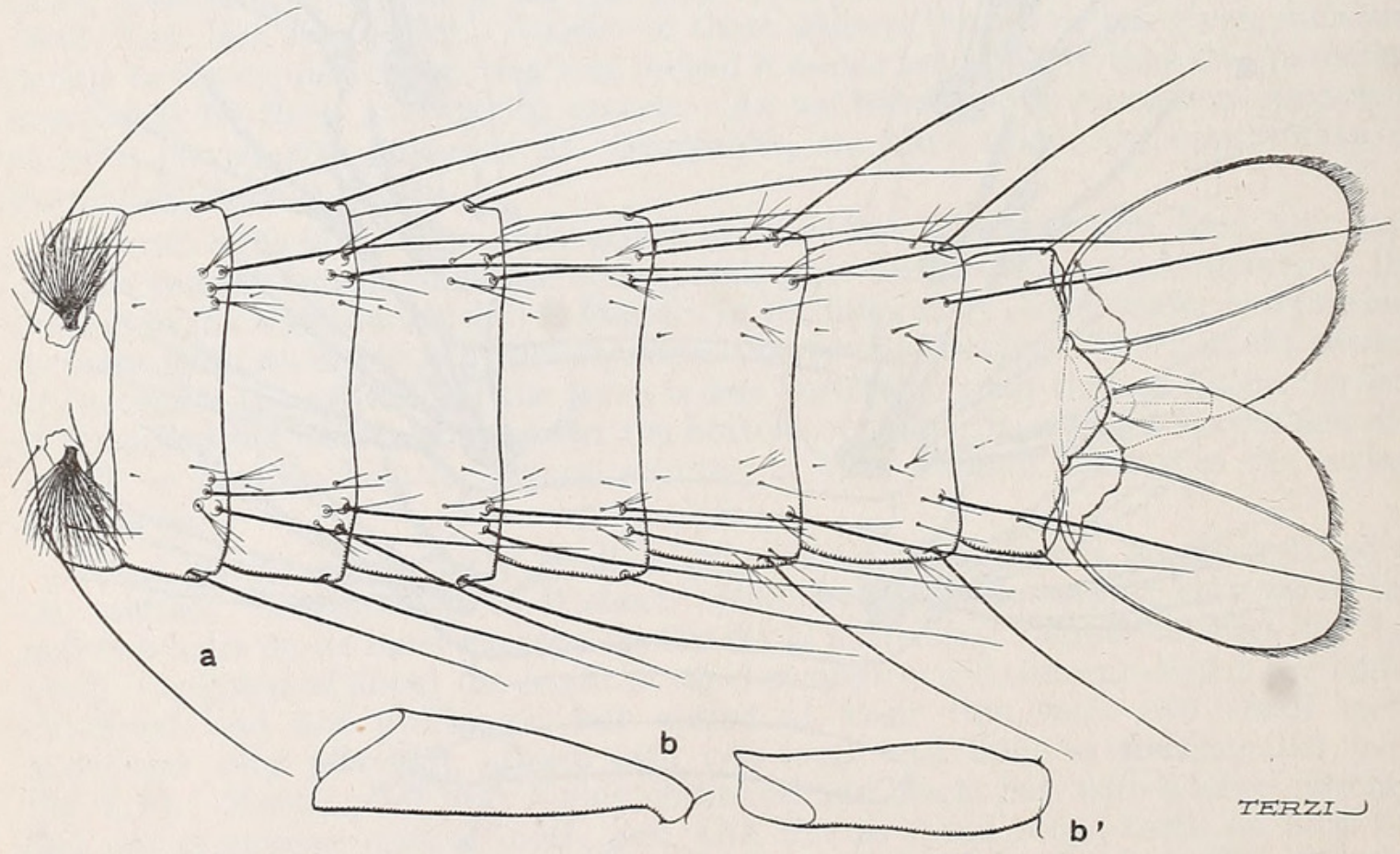

Fig. 3. Pupa of Megarhinus brevipalpis, Theo.: $a$, dorsal view of abdomen ; $b, b^{\prime}$, respiratory trumpets.

Abdomen. The paddles (fig. $3, a$ ) are large; the greatest length being a little over, and the greatest breadth a little under $2 \mathrm{~mm}$., the ratio being $1 \cdot 1$ to 1 . The midrib is well developed and divides the paddle into two unequal parts, the external portion being larger and longer than the internal. There are no setae at the distal end of the midrib. The external buttress is moderately well developed. The paddle bears a short fringe which, however, extends forwards on the external border only a short distance (about one-third of the external border). The surface of the paddles 
is slightly granular or shagreened. The terminal processes at the posterior end of the abdomen bear rather stout single or double setae, or a small tuft of three to five hairs. The dorsal abdominal setae are arranged as shown in the figure (fig. $3, a$ ) and therefore mention need be made of only the more important elements. The lateral setae (A) are extremely long (nearly $2 \mathrm{~mm}$.) and strong on segments $\mathrm{i}$ to vii ; they are single and pubescent or slightly subplumose. The sublateral setae (B) are present on segments ii to vii, are highly developed, very long, and similar to the setae of the lateral row. The submedian setae (C) appear to be present only on segments ii to $\mathrm{v}$ and are situated unusually far externally, close to the sublateral setae; they are similar to the lateral setae on segments iii to $\mathrm{v}$, and on segment ii are modified into strong tufts and displaced somewhat inwards. The dendritic tuft on segment $i$ is well developed, dark-coloured, and highly branched. The ventral abdominal setae are all small or relatively small and do not require special description. The abdominal stigmata are conspicuous.

Habitat.-Sekondi, 19.vi.1920 (E. E. Grey) ; Nsawam, a station about twenty-five miles north of Accra and on the fringe of the thick forest zone, 24.vi.1920; found in a rot-hole in the stump of a large silk-cotton tree (Eriodendron anfractuosum).

\section{Uranotaenia balfouri, Theo.}

LARVA.-The larva of this species was described by Wesché (Bull. Ent. Res. i, p. 50). Having recently had the opportunity of examining several specimens of this larva at higher magnifications than those employed by Wesché, we should like to supplement his description as follows :-The larva when fully grown is about $3 \mathrm{~mm}$. in length, the head is elongated, length about $0.6 \mathrm{~mm}$., breadth about $0.5 \mathrm{~mm}$. ; the antennae, sparsely clothed with spicules, are very dark brown and short, length about $0.14 \mathrm{~mm}$., bearing in place of a hair-tuft a single small hair a little before the middle. The pre-antennal tuft of Lang is a very small tuft of about three hairs ; the outer post-antennal a tuft of three, four or more longish hairs, and the inner and middle post-antennals are stout and spine-like, similar to those of $U$. alboabdominalis. The mental plate is small, situated unusually far anteriorly, with a pointed central tooth and five or six smaller teeth on each side of it.

Thorax relatively broad, length about $0.7 \mathrm{~mm}$., greatest breadth about $0.9 \mathrm{~mm}$. The dorso-lateral setae composed of long, subplumose hairs arising from small chitinised plates, which bear also-especially those on the posterior third-small hook-like spines. On each side of the dorsum, in a sublateral position, is an anterior and a posterior tuft, the latter being the larger and composed of about a dozen hairs.

Abdomen bearing long lateral setae only on the first two segments. Eighth segment with two large lateral chitinous plates practically enveloping the whole segment, and a second pair of smaller chitinous plates posteriorly between the bases of the siphon and the anal segment. Comb set at the posterior margin of the large lateral chitinous plate, composed of five to eight large, pointed spines with fringed bases, which are graded, the longest being the third from the ventral end of the row. Wesché figures the comb but shows the longest spine at one end of the row. The siphonal, subsiphonal and anal tufts are well developed and composed of about six, six, and twelve hairs respectively, those of the subsiphonal tuft being subplumose and the others simple. The tufts situated about the middle of the siphon are composed of about twelve hairs. The pecten extends to slightly beyond the middle of the siphon, and is formed of about nine to twelve delicate, fringed scales somewhat similar to those of $U$. alboabdominalis. Anal segment completely chitinised, almost twice as long as broad, the posterior margin fringed with small spines and bearing on each side a tuft of four to six hairs. Beard poorly developed. Dorsal setae two to four above and two below on each side in the specimens examined. Anal papillae small, subequal, tapering slightly and ending in blunt points. 
PuPA.-The pupa is small, length about $2.8 \mathrm{~mm}$. when extended, not very highly chitinised but partly infuscated. The following description is based on the examination of two (male and female) pelts.

Cephalothorax infuscated anteriorly and posteriorly. Respiratory trumpets (fig. 4, a) somewhat infuscated at base and apex, short, length about $0.3 \mathrm{~mm}$., straight, with moderately wide openings; ratio of length of meatus to total length of trumpet about 1 to $1 \cdot 4$. Cephalothoracic setae well developed and arranged as usual ; dorsal setae tufts of about six hairs.

Abdomen (fig. 4) slightly infuscated, especially the sixth and seventh segments. Paddles of the shape characteristic of the genus; length about $0.43 \mathrm{~mm}$., greatest breadth about $0 \cdot 26 \mathrm{~mm}$., ratio 1.6 to 1 . The midrib and external buttress are well developed, and the distal half of the paddle is fringed with small denticles, which are largest and strongest on the outer border. The single seta at the distal end of the midrib is very small.

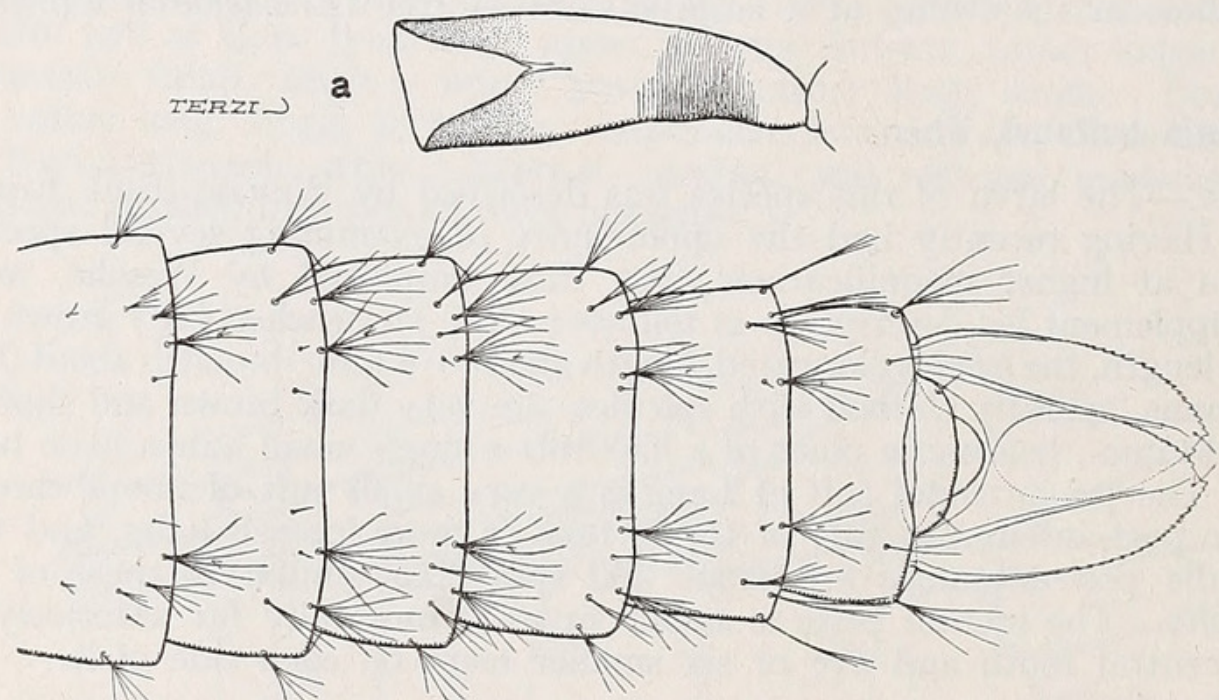

Fig. 4. Uranotaenia balfouri, Theo., dorsal view of abdomen of pupa : $a$, respiratory trumpet.

The dorsal abdominal setae are moderately well developed. The lateral setae (A) on segment viii are small, inconspicuous tufts composed of four very delicate hairs; on segment vii a rather long, delicate hair sub-divided at its end; and on segments iii to vi tufts of usually four hairs, which are long and delicate. The sublateral setae (B) on segments iv to vii are tufts of about six to ten long, delicate hairs (the more anterior segments bearing the larger tufts), which reach across to near the posterior margin of the following segment. The submedian setae (C) on segments iii to vii are long tufts of delicate hairs similar to the sublateral setae. The dendritic tufts on segment ii are moderately large; those on segment $\mathrm{i}$ are well developed and composed of about a dozen primary branches which are subplumose but not greatly branched.

Habitat.-Accra, and Ofako, a village about nine miles north of Accra on the road to Nsawam, v.1922. At both places the larvae were found in pools covered by the water-weed, Pistia stratiotes. The larvae in appearance, in habits, and in the position they assumed at the surface of the water, resembled young larvae of Mimomyia splendens, but could be distinguished with the aid of a hand lens by the smaller size of the head. 
Uranotaenia inornata, Theo.

LARVA.-The larva is small, length when fully grown about $3.5 \mathrm{~mm}$., and has a very dark-coloured head. The following description is based on an examination of two larvae.

5 Head (fig. 5) very highly chitinised and almost black; in the fully grown larva the length and the greatest breadth are about equal $(0.7 \mathrm{~mm}$.). Antennae very dark, short $(0.6 \mathrm{~mm}$.), almost cylindrical, bearing a single small hair in place of a tuft, and furnished at the distal end with the usual setae and sensory processes. Anterior

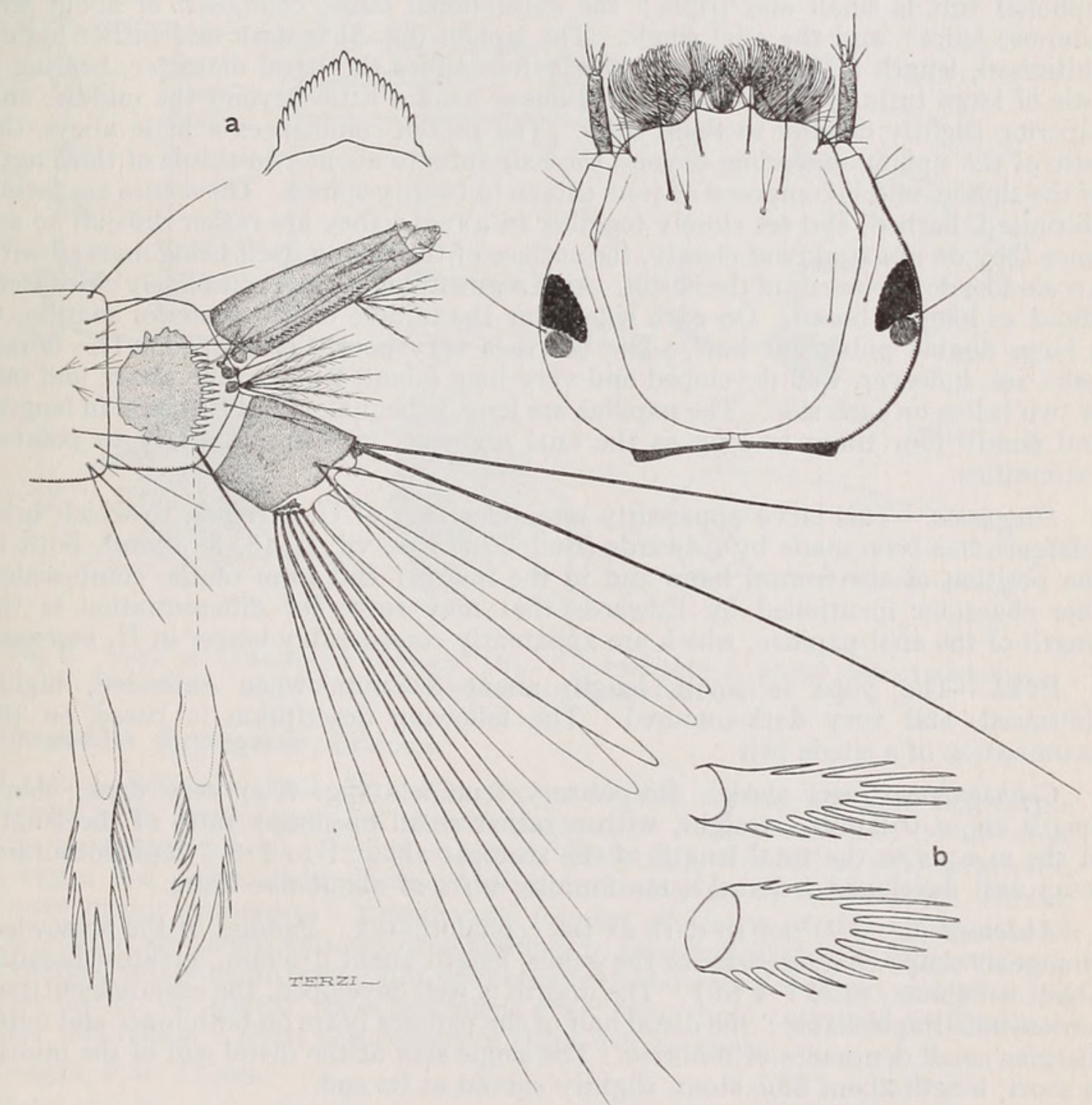

Fig. 5. Uranotaenia inornata, Theo., head and terminal segments of larva : $a$, mental plate ; $b$, scales of pecten.

dorsal hairs situated far forwards, the pre-antennal hairs of Lang single, stout, long and tapering, the outer post-antennals being tufts of about five hairs, the mid postantennals and the inner post-antennals placed rather close together, the former represented by a single, long, slender hair, and the latter by a very small delicate hair. Eyes large, situated in the angles at the widest part of the head. Mental plate (fig. $5, a$ ) very dense, furnished with numerous very small teeth, the central one somewhat larger than the others. 
Thorax broad, about $1 \mathrm{~mm}$., bearing large tufts of subplumose hairs and dorsally, on each side of the middle third, two very long black pubescent hairs which reach forwards beyond the anterior margin of the head. All the larger thoracic setae arise from chitinised tubercles.

Abdomen not very hairy. Lateral abdominal setae long and triple on the first two segments, thereafter single and smaller. Comb (fig. 5) composed of about a dozen spines set in a transverse row at the margin of a large chitinous plate on the lateral aspect of the eighth segment, the spines are rather feebly chitinised, and have a large pointed median barb and a fringe of smaller barbs on each side of it. The siphonal tuft is small and triple; the subsiphonal large, composed of about five plumose hairs; and the anal single. The siphon (fig. 5) is dark and rather highly chitinised, length (about $0.6 \mathrm{~mm}$.) nearly four times the basal diameter, bearing a pair of large tufts of three to six subplumose hairs a little beyond the middle, and tapering slightly distally to those tufts. The pecten commences a little above the base of the siphon, extending beyond the hair-tufts to about two-thirds of the length of the siphon, and is composed of from fifteen to twenty spines. The spines are feebly chitinised, barbed, and set closely together in a row; they are rather difficult to see since they do not stand out clearly, the surface of the siphon itself being marked with a scale-like development of the chitin. Anal segment highly and completely chitinised, about as long as broad. On each side, near the middle of the posterior margin, is a large double pubescent hair. The beard is very poorly developed. The dorsal hairs are, however, well developed and very long (about $2 \mathrm{~mm}$.), one above and one or two below on each side. The papillae are long, subequal, about $0.9 \mathrm{~mm}$. in length, and nearly four times as long as the anal segment, tapering regularly to pointed extremities.

Diagnosis.-This larva apparently resembles that of $U$. nigripes, to which brief reference has been made by Edwards (Bull. Ent. Res. vii, p. 15, footnote), both in the position of the frontal hairs and in the number and form of the comb-scales. One character mentioned by Edwards that may serve for differentiation is the length of the anal papillae, which are apparently considerably longer in $U$. inornata.

PuPA.-The pupa is small, length about $3.5 \mathrm{~mm}$. when extended, highly. chitinised, and very dark-coloured. The following description is based on the examination of a single pelt.

Cephalothorax very dark. Respiratory trumpets (fig. 6, a) very dark, short, length about $0.3 \mathrm{~mm}$., straight, with a rather small opening; ratio of the length of the meatus to the total length of the trumpet about 1 to $1 \cdot 3$. Cephalothoracic setae well developed; dorsal setae forming tufts of about five hairs.

Abdomen (fig. 6, $b$ ) not so dark as the cephalothorax. Paddles of the somewhat triangular shape characteristic of the genus, length about $0.5 \mathrm{~mm}$., greatest breadth about $0.34 \mathrm{~mm}$., ratio 1.4 to 1 . The midrib is well developed, the external buttress almost indistinguishable; the distal half of the paddles bears on both inner and outer margins small denticules or fimbriae. The single seta at the distal end of the midrib is short, length about $85 \mu$, stout, slightly curved at its end.

The arrangement of the abdominal setae, except in the following instances, calls for no special mention. The lateral setae (A) on segment viii are large tufts, about half the length of the paddles, composed of nine subplumose hairs which are occasionally branched at their tips; on segment vii small, insignificant tufts of two or three hairs; on segments $\mathrm{v}$ and vi long single hairs ; and on segments iii and iv similar but shorter and more delicate single hairs. The sublateral setae (B) on segments iv to vi are long, single or double, reaching across the following segments or further; on segment vii they are smaller, reaching only about half-way across the eighth segment. The submedian setae (C) on segments iv and $\mathrm{v}$ are long, single hairs, reaching beyond the posterior margin of the following segments ; on segments 
vi and vii shorter, single hairs, reaching about half-way across the following segments. The dendritic tufts (fig. 6, c) on segment i are large, composed of about ten primary branches. On segment ii there are small dendritic tufts similar to those found in the genus Culex.

Habitat.-Kpong, iv.1922; larvae collected from rock-pools near the River Volta. The pools were fully exposed to the sun, and the water in them was very hot. Mosquito larvae, mostly of Aëdes (S.) vittatus, abounded in these pools, and with them were a few larvae of $U$. inornata.

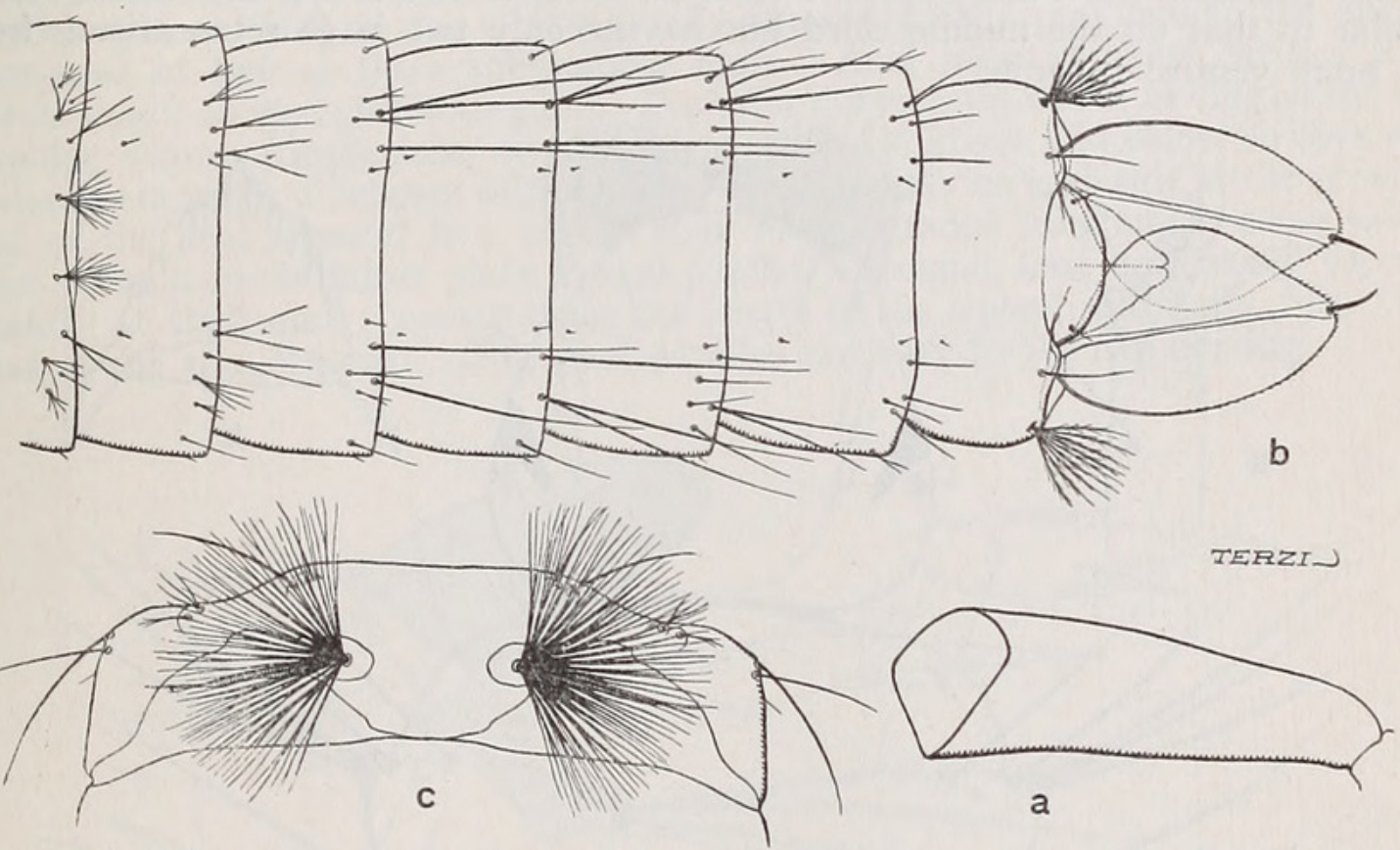

Fig. 6. Pupa of Uranotaenia inornata, Theo. : $a$, trumpet; $b$, dorsal view of abdomen ; $c$, dendritic tufts on first segment of abdomen.

Eretmopodites chrysogaster, Graham.

LARVA.-Edwards (Bull. Ent. Res. iii, p. 47) has figured without description the larvae of $E$. chrysogaster, but the drawings are on a small scale and do not show certain important points. He has elsewhere (Bull. Ent. Res. iii, p. 385) mentioned in a key a few points distinguishing this larva from that of $E$. inornatus, Newst. We have in our possession a considerable number of larvae of this mosquito and larval pelts of specimens actually bred through to the adult stage. In some respects, for example, in having no lateral tuft on the seventh abdominal segment and in having a small tuft on the siphon, these specimens differ from those examined by Edwards, and for this reason a short description of them will be given.

Length, 9 to $12 \mathrm{~mm}$.

Head (fig. 7) highly chitinised, not very large, without conspicuous hair-tufts. In lateral view oval ; in dorsal view rounded and rather narrow anteriorly, broader posteriorly, with rounded posterior angles. Greatest breadth slightly more than the length, but less than the breadth of the thorax (ratio 3 to 5). On the anterior portion of the dorsum and on each side are three setae arranged in a triangle; the anterior one rather long, single; the internal, small, delicate, double; the external, rather longer, double. The dorso-lateral seta situated on a level with the base on the antenna on each side, long, single or double. There are a few other setae on the head, all quite small, one of which arises in the posterior eye spot. Antenna (fig. 7, a) dark brown, cylindrical, short, scarcely projecting as far forwards as the ends of the mouth-brushes; not spiculated and without hair-tuft, but bearing at about its 
middle and on its inner aspect a single hair. Mental plate (fig. $7, b$ ) traingular, highly chitinised, with a moderately large pointed central tooth and seven or eight small pointed teeth on each side of it.

Thorax. Setae on the anterior third (first thoracic segment) small; the one most highly developed is situated dorso-laterally, arising from a small chitinous plate and single. On the middle third the dorso-lateral seta is well developed, long, strong, single; the lateral tuft is double, composed of a long single seta dorsally and three similar setae ventrally arising from contiguous chitinised tubercles. On the posterior third there appears to be no dorso-lateral seta ; the lateral tuft is similar to that on the middle third but having only two large setae arising from the more ventral tubercle.

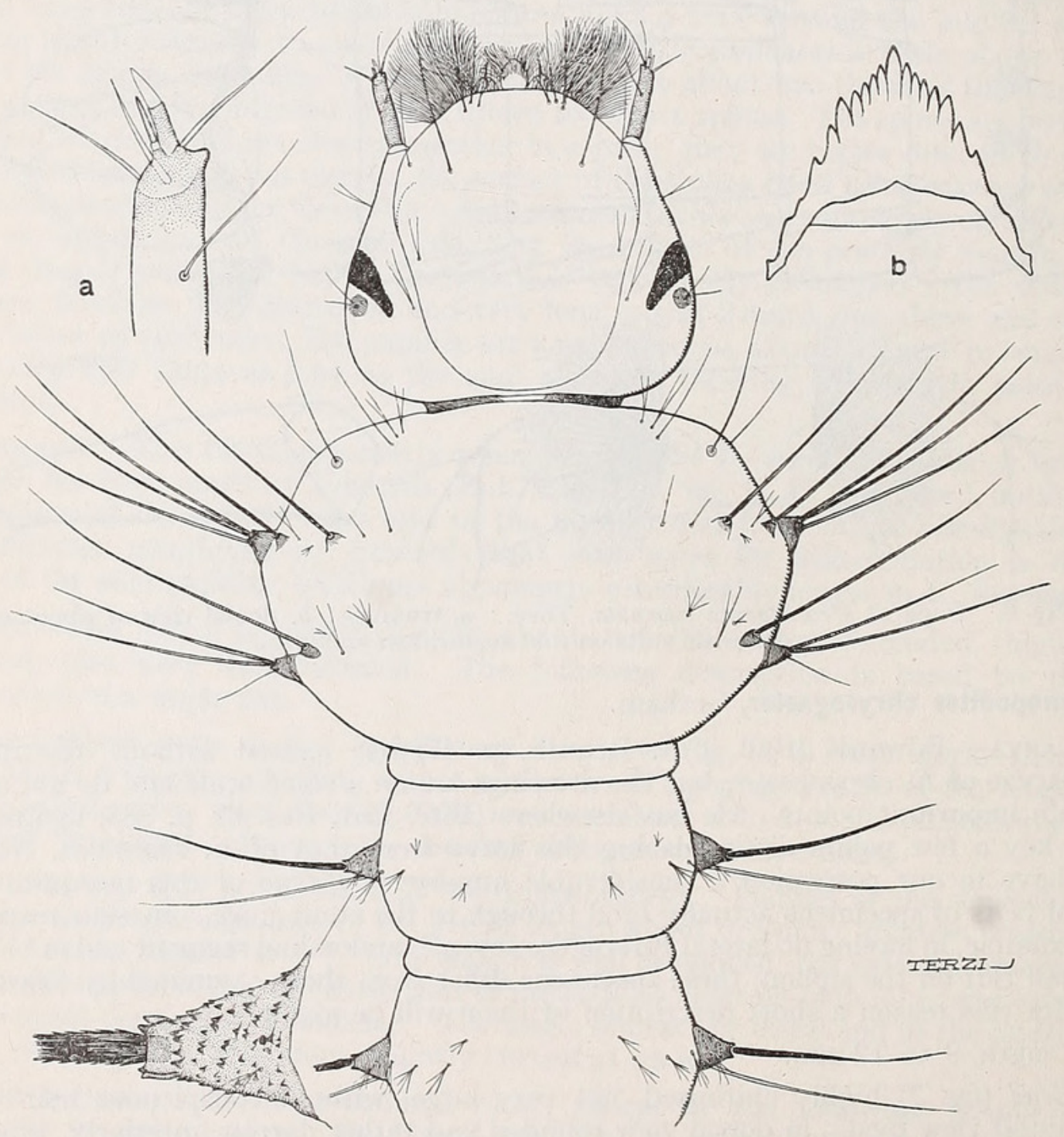

Fig. 7. Larva of Eretmopodites chrysogaster, Graham, anterior portion of body: $a$, antenna; $b$, mental plate.

Abdomen. The abdominal setae are small and inconspicuous, with the exception of the lateral elements. On each side of segments iii to $\mathrm{v}$ are, dorsally a stout, relatively short, single seta arising from a well-developed conical chitinised tubercle, and ventrally a more delicate single seta arising from a small tubercle; on segments $\mathrm{i}$ and ii these two setae are situated close together and dorsally, and arise from a common double chitinised tubercle ; from segment vi the ventral seta is absent; 
on segment vii only small delicate hairs are present; and on segment viii are a well developed tuft (the subsiphonal tuft) ventral to the siphon, composed of 3 to 7 subplumose hairs, two very small tufts dorsally, at the base of the siphon, and a very small delicate tuft at the base of the anal segment. Comb (fig. 8) composed of about thirty (19 to 33 ) spines arranged in an irregularly triangular patch; each spine is highly chitinised, with several sharply pointed teeth, one of which is usually somewhat longer and larger than the others. Siphon (fig. 8) well chitinised, dark brown, short, and forming with the eighth segment an angle extremely obtuse anteriorly; ratio of length to basal breadth about 2 to 1 . Pecten composed of 1 to 4 dark brown barbed spines. Tuft on the siphon small, situated a little proximal to the middle, composed of two or three subplumose hairs. Anal segment short, with a small dorsal saddle-shaped chitinous plate. Posterior dorsal setae about as long as the anal papillae, strong, subplumose, usually single or double above and below on each side. Lateral seta small, a delicate tuft of hairs. Subventrally on each side at the posterior end of the anal segment is a row of four strong graded subplumose setae arising from a common chitinised plate. Anal papillae subequal, long and broad, tapering slightly at their ends; nearly twice the length of the siphon and more than twice that of the anal segment. The anal papillae are very frequently missing.

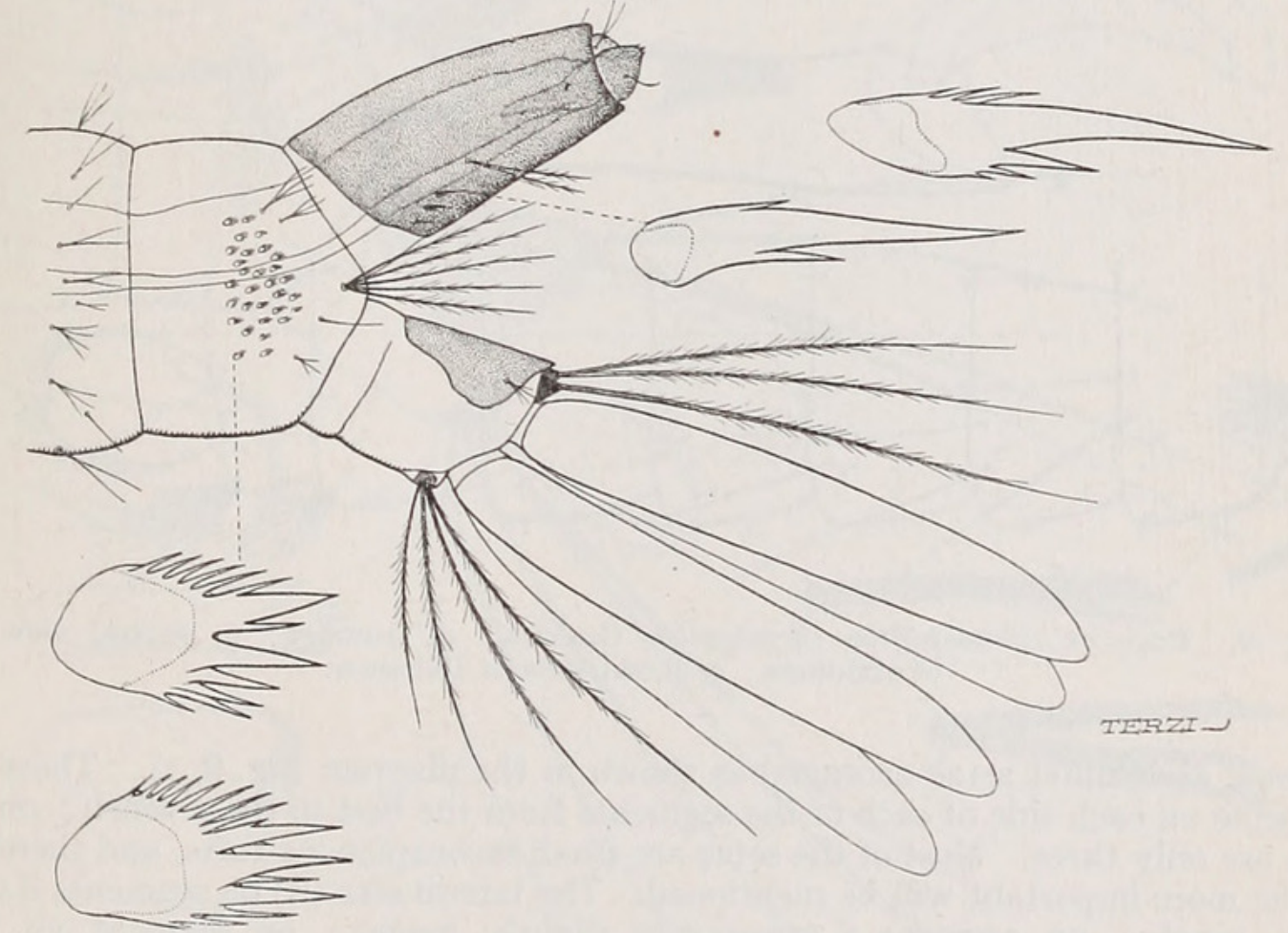

Fig. 8. Larva of Eretmopodites chrysogaster, Graham, terminal segments.

PUPA.-Edwards (loc. cit.) has also figured the pupa, but the remarks made when dealing with the larva apply also to this figure. Bacot has figured the paddles and the terminal segments only. A fuller description of the pupa will therefore be given.

Length, when fully extended, $7 \mathrm{~mm}$. to $8.5 \mathrm{~mm}$. The pupa is well chitinised, and its general form is well shown in Edward's figure.

Cephalothorax well chitinised. Wing-cases rather loosely attached to the sides. Respiratory trumpets (fig. 9 a) shaped like the corolla of a foxglove, opening not very wide ; length about $0.7 \mathrm{~mm}$., ratio of length of the closed portion (meatus) to total length about 1 to $1 \cdot 4$. Cephalothoracic setae arranged much as in Aëdes argenteus (Stegomyia fasciata). Post-ocular and antero-thoracic setae very small and inconspicuous. Dorsal setae long, strong, single ; slightly subplumose and often divided 
at the end. Supra-alar seta a small tuft of about five fine hairs. Postero-thoracic setae: internal and median, long stout black setae, subplumose, single; external, a small tuft of about five delicate hairs.

Abdomen. The paddles (fig. 9, c) are relatively small, and bear a long fringe on both the inner and outer borders; length averaged in five specimens $716 \mu$, greatest breadth $496 \mu$, the ratio being about $1 \cdot 4$ to 1 . Midrib moderately well developed. At the distal end, slightly to the outer side of the midrib, is a long, subplumose, single seta $\left(\mathrm{P}^{\prime}\right)$; length averaged $537 \mu$, that is, rather more than the breadth of the paddle; this seta is sometimes divided at its end into a number of hairs, when this is the case it is much shorter.
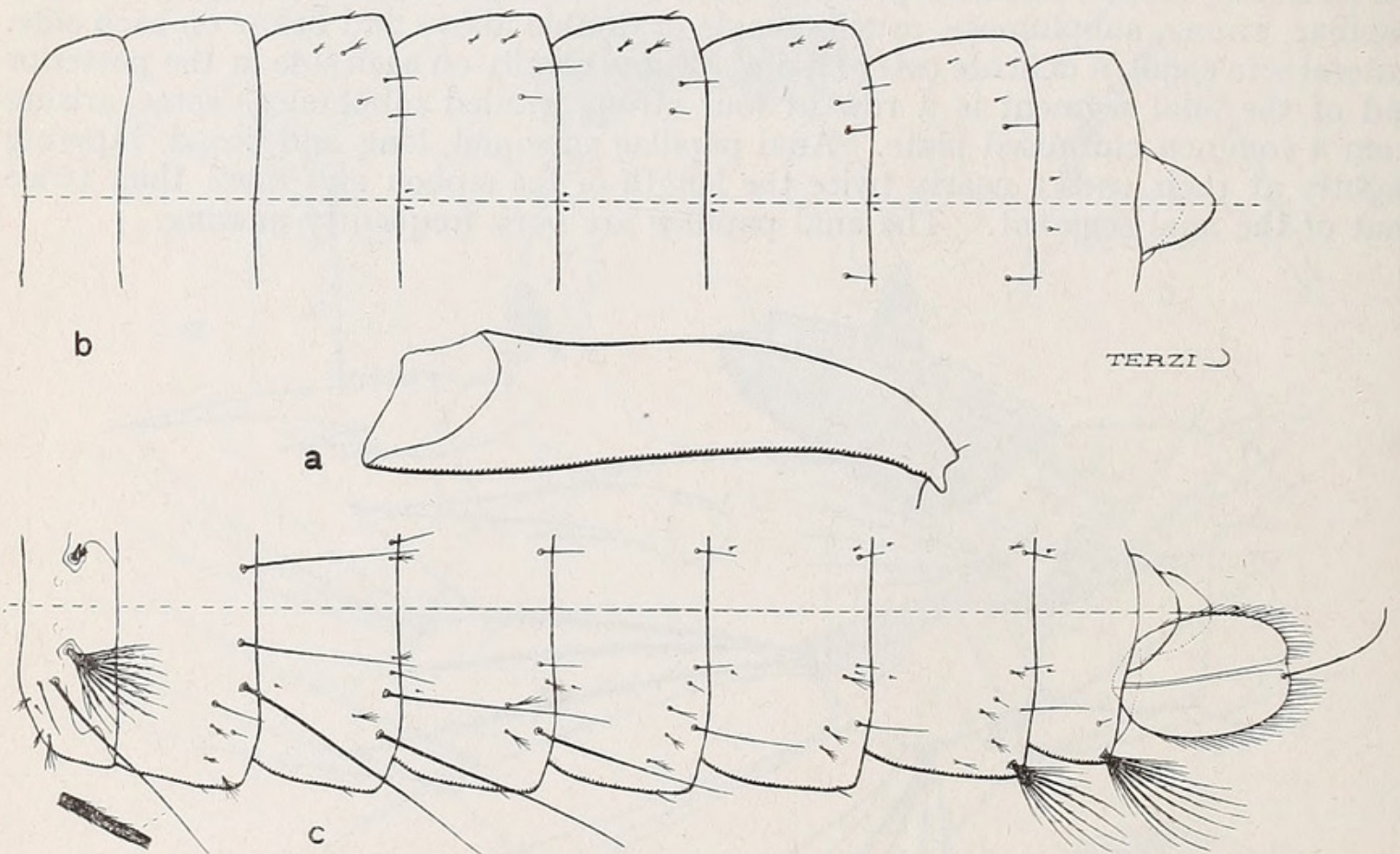

Fig. 9. Pupa of Eretmopodites chrysogaster, Graham : $a$, trumpet; $b$, ventral view of abdomen ; $c$, dorsal view of abdomen.

Dorsal abdominal setae arranged as shown in the diagram (fig. 9, c). There are eight setae on each side of each of the segments from the first to the seventh; on the eighth are only three. Most of the setae are small inconspicuous tufts, and therefore only the more important will be mentioned. The lateral seta (A) on segments ii to vi minute, single; on segment i apparently slightly longer; on segment vii well developed tufts, as long as or longer than the eighth segment, composed of about six (three to seven) dark, subplumose hairs ; on segment viii larger tufts, rather longer than the paddle, composed of about six (four to nine) dark, subplumose hairs ; both the latter tufts often have additional small subsidary basal hairs. The sublateral setae are recognisable on segments iii to vii at least; on segments $\mathrm{v}$ to vii they are moderately stout and long, extending about half-way across the succeeding segment ; on segments iii and iv they are long, strong, black setae, slightly subplumose, extending considerably beyond the posterior margin of the succeeding segments. On segment iii a little internal to the sublateral seta is a similar long, strong, black seta. On segment ii this seta and the sublateral seta are apparently displaced inwards; both setae are similar to the sublateral setae on segments iii and iv, but the inner one is rather shorter. The submedian setae are not highly developed: in this situation, on segments iii to vii, are small stout single setae. The tuft on 
segment $\mathrm{i}$ is moderately well developed, and is composed of about ten (six to thirteen) dark plumose hairs ; the antero-internal seta is small but stout ; the antero-external long, strong, black, slightly subplumose.

Ventral abdominal setae all very small and inconspicuous; arrangement as in Aëdes argenteus (Stegomyia fasciata). Postero-lateral and medio-lateral small tufts. The arrangement of the setae is shown in the diagram (fig. 9, b).

Habitat.-Aburi, 21.xi.1920, in cut bamboos, and in small collections of water in banana leaves lying on the ground; Koforidua, vii.1916, in pawpaw tree stump ; Nsawam, 1.i.1920, in disused tins near the Rest House and in a hollow stump of a pawpaw tree; Taimang, 18.iii.1922, in pawpaw tree stumps.

\section{Eretmopodites quinquevittatus, Theo.}

LARVA.- The larva is similar to that of E. chrysogaster, and it is therefore only necessary to describe the more important points of difference.

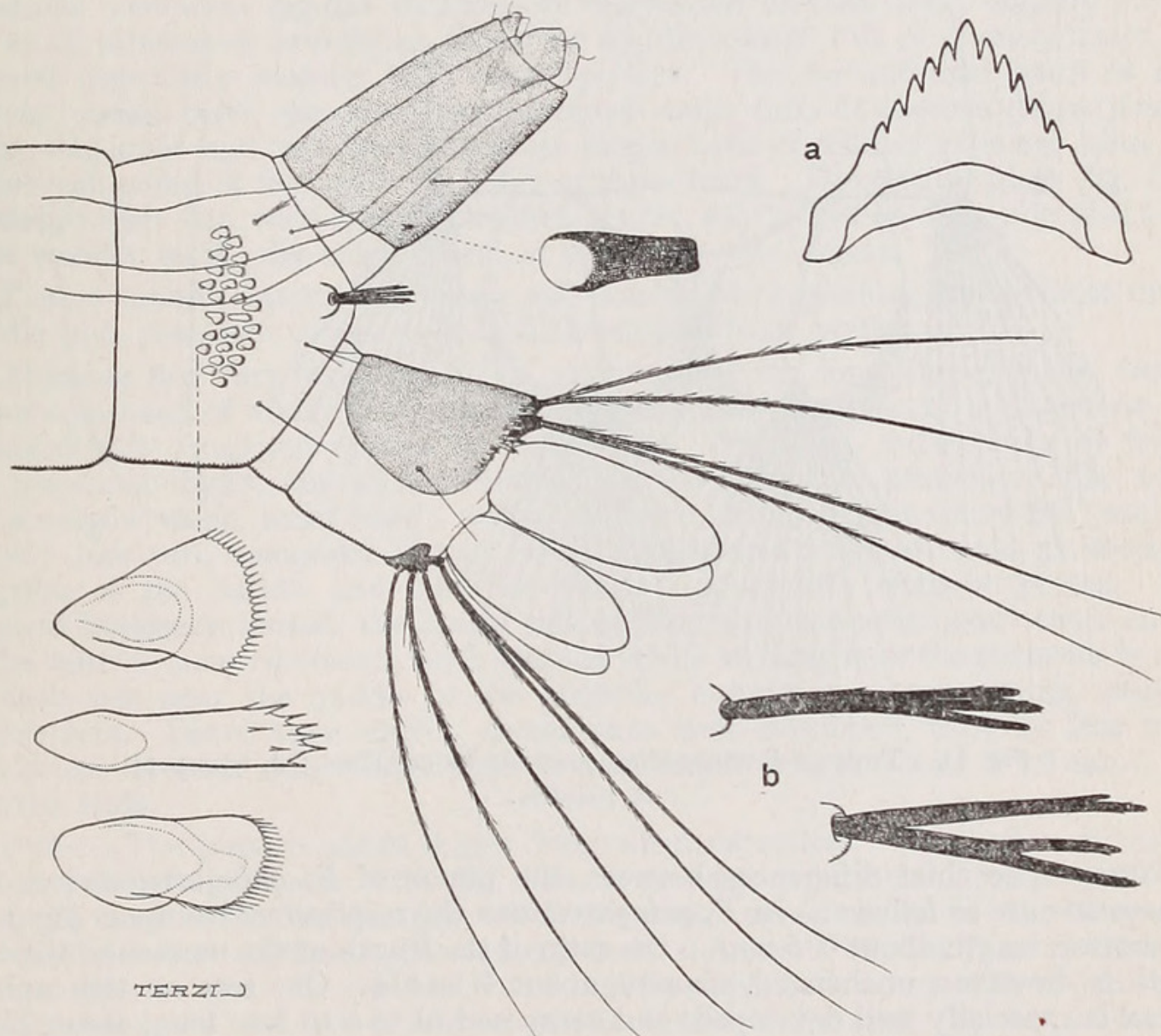

Fig. 10. Larva of Eretmopodites quinquevittatus, Theo., terminal segments of abdomen : $a$, mental plate; $b$, subsiphonal setae.

The head is smaller and narrower, the greatest breadth almost the same as the length, and about half the diameter of the thorax. Mental plate (fig. 10, a) with, apparently, six teeth on each side of the middle tooth. The dorso-lateral setae on the middle third of the thorax more highly developed and forming a large tuft, half of fiwhich is composed of short and half of long hairs. There are no short, stout setae on the sides of the abdomen similar to those of E. chrysogaster. The subsiphonal tuft is, however, a short, stout, dark-coloured seta arising from a chitinised tubercle and divided into two or three tapering branches (fig. 10, b). The comb is composed of about twenty-five small scales arranged in a triangular patch; each scale is short, 
feebly chitinised, and finely fringed at its blunt distal end. The siphon (fig. 10) is shorter than that of E. chrysogaster, and is less than twice as long as the basal breadth, the ratio of length to basal breadth being about 1.5 to 1 ; it bears in place of a tuft a single long seta on its basal third, and has either no pecten or only a single spine. The dorsal and subventral setae at the posterior margin of the anal segment are longer than in E. chrysogaster.

Diagnosis.-The larva of E. quinquevittatus may be distinguished from that of $E$. chrysogaster by the characters given above. We have not had an opportunity of examining the larva of $E$. inornatus, the only other African species of which the larva has apparently been described, but from the characters given by Edwards it is clear that it more closely resembles E. quinquevittatus; indeed the only point mentioned which might serve to separate them, namely, the two-haired tuft on the siphon of E. inornatus, is not likely to be sufficient, if one may judge from the range of variations of this tuft in other mosquitos.
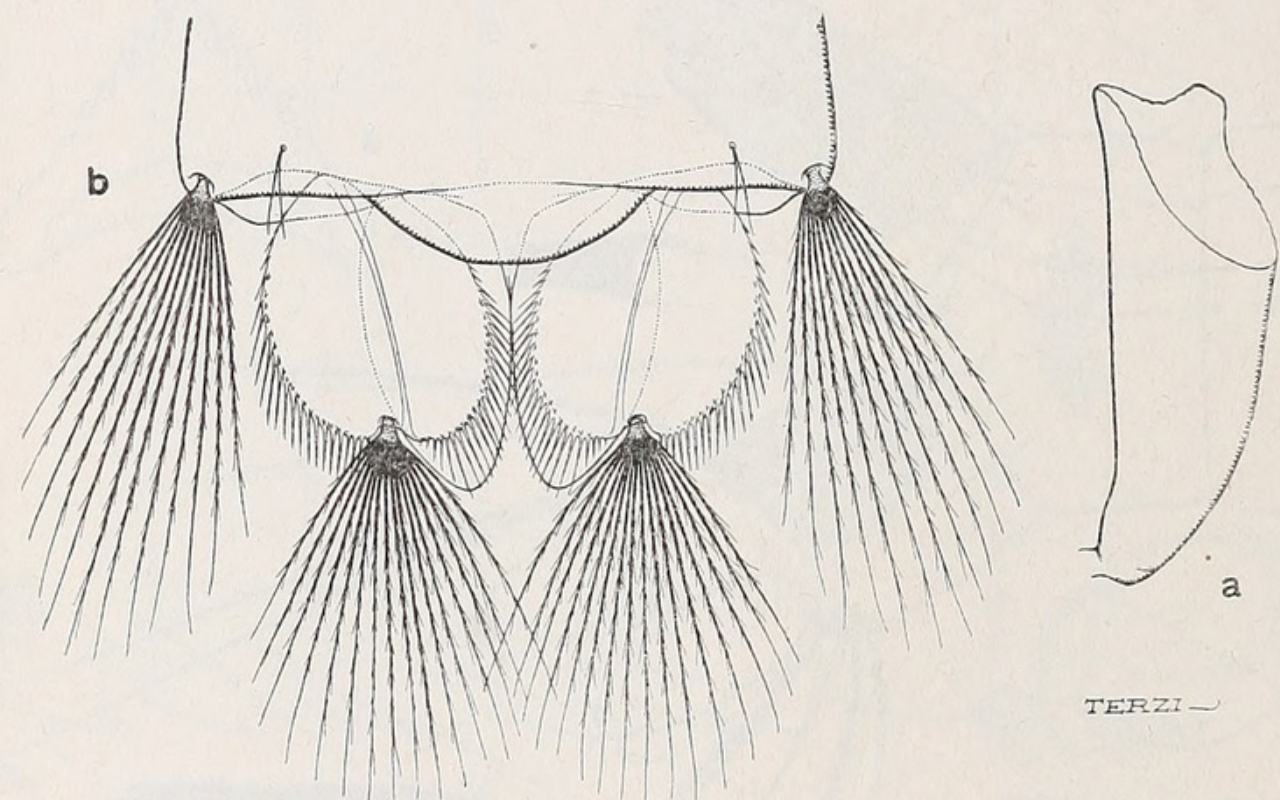

Fig. 11. Pupa of Eretmopodites quinquevittatus, Theo.: a, trumpet; $b$, paddles.

PUPA.-The chief differences between the pupae of $E$. quinquevittatus and $E$. chrysogaster are as follows:-In E. quinquevittatus the respiratory trumpets (fig. 11, a) are shorter, length about $0.5 \mathrm{~mm}$. ; the ratio of the length of the meatus to the total length is, however, unchanged, namely, about 1 to $1 \cdot 4$. One seta on the cephalothorax is especially well developed, and composed of two to four long, stout, black, pubescent branches; this seta is apparently the median post-ocular seta, but as both the specimens examined were pelts we were unable to be certain of this. The paddles (fig. $11, b$ ) are relatively very small and bear a long fringe; length about $390 \mu$, greatest breadth about $360 \mu$. In the male the sheaths of the claspers project posteriorly beyond the ends of the paddles. At the distal margin, slightly to the outer side of the end of the midrib, is a very large tuft composed of ten to seventeen long, subplumose, black hairs ; this tuft is about $0.7 \mathrm{~mm}$. to $0.8 \mathrm{~mm}$. long, that is, much longer than the paddle. The dorsal abdominal setae are similar to those of $E$. chrysogaster, but the lateral setae on segments vii and viii are rather larger and more subdivided; the sublateral setae on segment vii very small and inconspicuous, on segments iv to vi larger than in E. chrysogaster; and the other strongly developed setae smaller than those of $E$. chrysogaster. The tufts on segment $\mathrm{i}$ are smaller and 
less expanded, composed of five to seven subplumose hairs. The rest of the abdominal setae do not apparently call for special mention.

Diagnosis. - The smaller size of the paddles and the large tufts at their distal ends suffice to distinguish this pupa from those of other known species of Eretmopodites.

Habitat.-Accra, 26.vii.1921, in water collected in disused tins near the European Hospital.

Ficalbia mediolineata, Theo.

LARVA.- The length of the larva when fully grown is about $5 \mathrm{~mm}$. It is palecoloured, with a bronze-brown siphon and çonspicuous dark lines on the anterior lateral angles of the thorax due to the coiled respiratory trumpets of the pupa which show through the larval cuticle.

Head (fig. 12) broad, length nearly $0.8 \mathrm{~mm}$. and greatest breadth about $0.9 \mathrm{~mm}$. Antennae somewhat similar to those of Mimomyia hispida, long, slightly curved, not at all infuscated, bearing at about the middle a large tuft of plumose hairs, and covered (especially basally) with large spicules. The pre-antennal hairs of Lang are very small tufts, the outer post-antennals large tufts of about a dozen plumose hairs, the inner and mid post-antennals longer tufts of similar plumose hairs, the former composed of five, and the latter of three hairs. The mental plate (fig. 12, a) is small, rather flat, with a large, pointed, central tooth, and on each side of it about eight smaller teeth, the most lateral of which are the largest.

Thorax broad; lateral tufts long and composed of plumose hairs, those on the middle and posterior thirds with well developed basal spines.

Abdomen not very hairy. Lateral abdominal setae long and plumose basally. Comb composed of about twelve small fringed spines arranged in a transverse row. Siphonal tuft composed of two or three rather long hairs, subsiphonal of four or five pubescent hairs, and anal of about four more delicate branches. The siphon has a narrow, dark, basal band ; length (about $1.2 \mathrm{~mm}$.) eight times the basal diameter ; hair-tuft, composed of two rather long simple hairs, situated at about the junction of the middle and posterior thirds; apparently without pecten. Anal segment highly chitinised, the dorsal side of the chitinised area about twice as long as the ventral, covered dorsally with spicules which are long near the posterior border ; on each side near the middle of the posterior margin is a long, strong, single or double seta. Beard very small; dorsal setae well developed, three or four above and below on each side. Anal papillae very small (length about $0.15 \mathrm{~mm}$.), with pointed ends.

PUPA.-The pupa is about $4 \mathrm{~mm}$. long when extended. When alive it rests at the surface of the water with the two very long respiratory trumpets directed forwards and either submerged with the long dorsal hairs of the second to fourth abdominal segments directed upwards and forwards and just reaching the surface film, or with the cephalothorax slightly depressed, a fact with which should be correlated the obsolete condition of the dendritic tufts on the first abdominal segment. It is rather top-heavy owing to the length of the trumpets.

Cephalothorax. Respiratory trumpets (fig. 13, a) straight, very long and narrow, dark brown, except the extreme base and the apical one-fifth or one-sixth, which is white. Length about $2.7 \mathrm{~mm}$., breadth in the middle about $70 \mu$; proximal end slightly wider, distal extremity with a narrow neck and a funnel-shaped opening. The ratio of the length of the meatus to the total length of the trumpet is about 1 to $1 \cdot 1$. The cephalothoracic setae are rather poorly developed and do not call for special mention, the dorsal setae are single and short.

Abdomen (fig. 13, $b$ ). The paddles are long and very narrow, length about $0.9 \mathrm{~mm}$., greatest breadth about $0.15 \mathrm{~mm}$., ratio 6 to 1 . The midrib is well developed, but the external buttress is practically wanting; there are no terminal setae, and the 


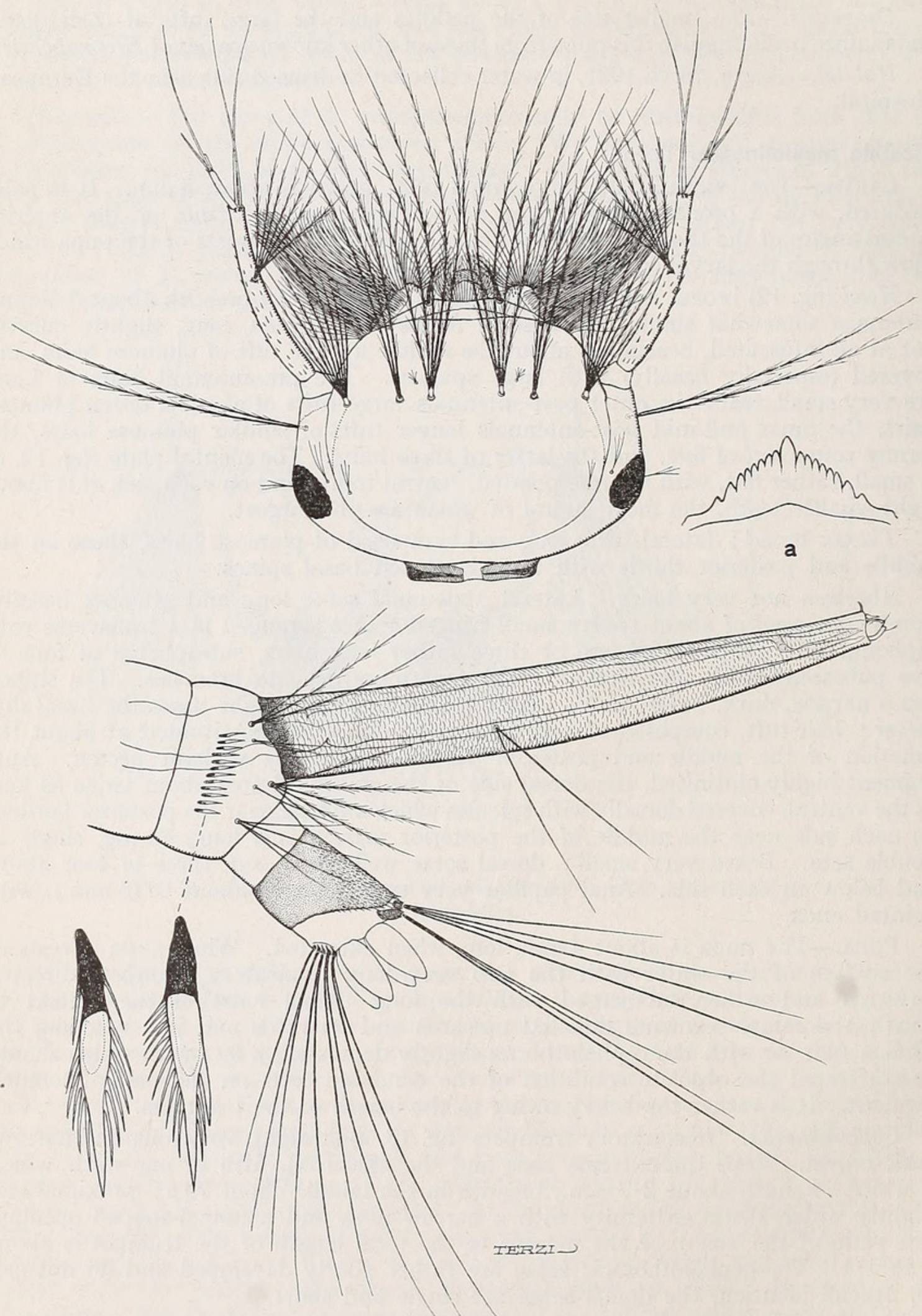

Fig. 12. Larva of Ficalbia mediolineata, Theo., head and terminal segments of abdomen : $a$, mental plate. 
fringe, which is composed of large tooth-like processes, extends completely round the paddles with the exception of the extreme base. The ninth segment is unusually large and in the female is furnished with two lateral processes covered by coarse spicules (fig. 13, $c, d$ ). The dorsal abdominal setae are well developed, the more important ones being conspicuous black tufts. The lateral setae (A) on segment viii are large tufts, reaching nearly to the middle of the paddles, composed of eight or nine pubescent hairs, on segment vii smaller tufts of two or three similar hairs, and on segments ii to vi very long, delicate, single hairs. The sublateral setae (B) on segment vii are tufts, reaching beyond the posterior margin of the eighth segment, of four pubescent hairs; on segments iv to vi similar but longer tufts of three hairs. The submedian setae $(\mathrm{C})$ on segment vii are very long tufts, reaching backwards beyong the middle of the paddles, composed of three pubescent hairs ; on segments iii to vi similar but shorter tufts of three hairs. The dendritic tufts on segment $\mathrm{i}$ are obsolete, being represented by small, stout, single setae.

Habitat.-Accra, v.1922 ; collected from a pool covered by water lettuce (Pistia stratiotes), near the station for the Weshiang railway line.

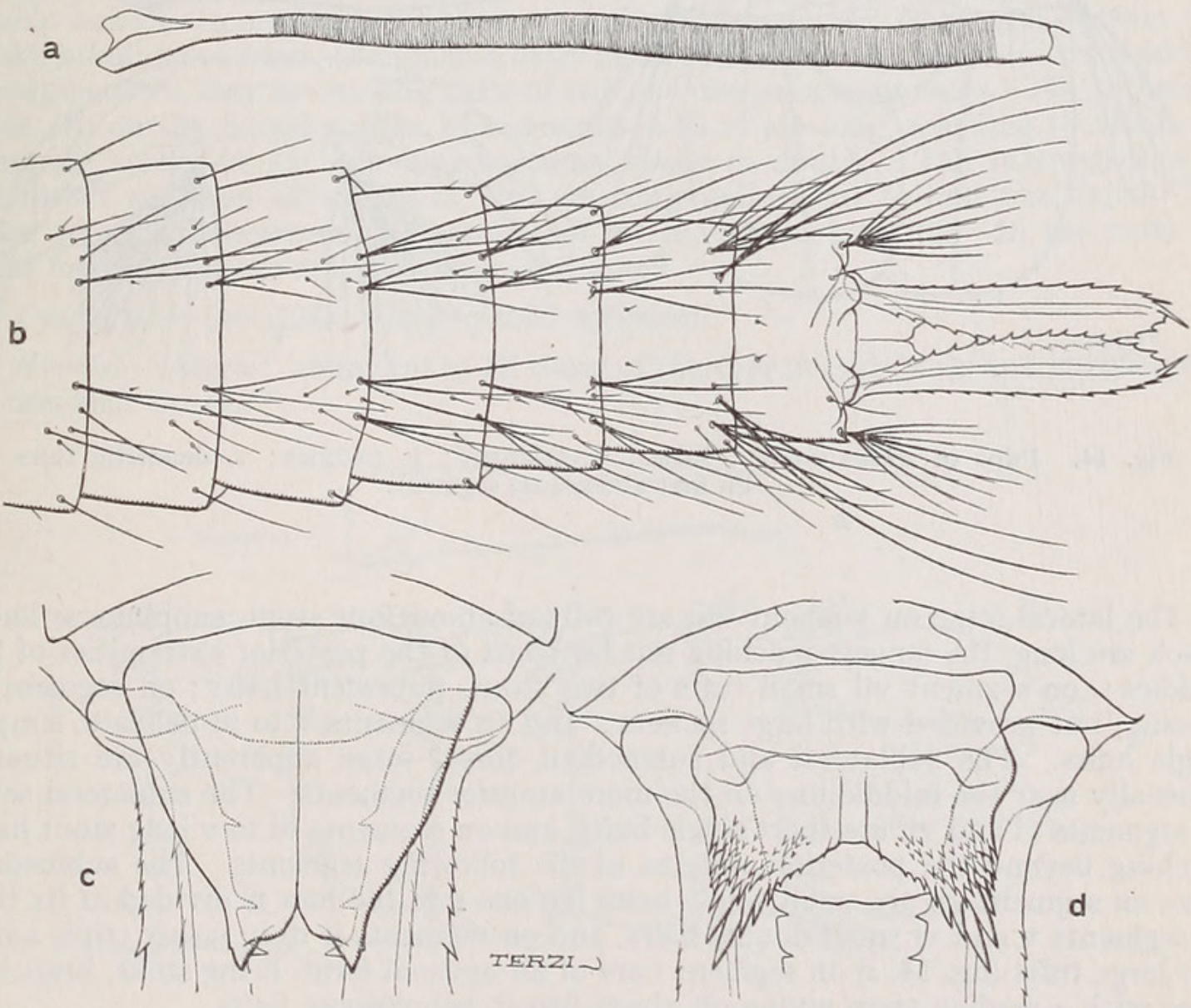

Fig. 13. Pupa of Ficalbia mediolineata, Theo. : $a$, trumpet; $b$, dorsal view of abdomen ;

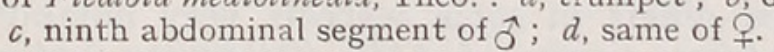

\section{Aëdes (Aëdimorphus) furcifer, Edw.}

LARVA.-The larva has not yet been identified.

PupA.-Only a single pupal pelt was obtained, and as some setae were missing from it a complete description cannot be given. The pupa is well chitinised and not very large; length when extended about $5 \mathrm{~mm}$. 
Cephalothorax. The respiratory trumpets (fig. 14, a) are short, narrowed both apically and basally, slightly infuscated basally, and with narrow apertures; length about $0.5 \mathrm{~mm}$., middle breadth about $120 \mu$, ration of the length of the meatus to the total length about 1 to $1 \cdot 26$.

Abdomen. The paddles (fig. $14, b$ ) are oval and small ; length about $0.6 \mathrm{~mm}$., greatest breadth about $0.4 \mathrm{~mm}$., only slightly more than half the breadth of the eighth abdominal segment. The external buttress is practically absent. The midrib is feebly developed and divides the paddle into two approximately equal halves. There is no fringe, but the posterior and external borders of the paddles bear a few small denticulations. The distal hair was unfortunately missing from both the paddles, but there appeared to be a socket for a large seta on the outer side of each midrib.
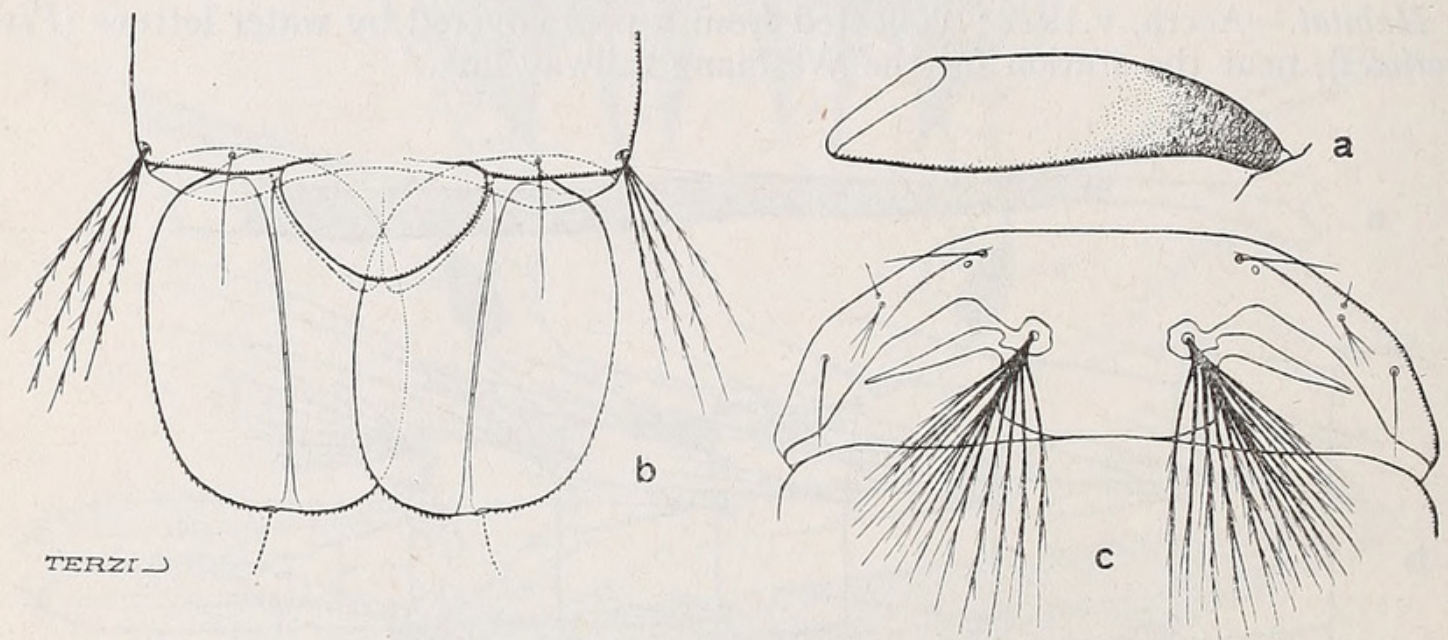

Fig. 14. Pupa of Aëdes furcifer, Edw. : $a$, trumpet; $b$, paddles; $c$, dendritic tufts on first abdominal segment.

The lateral setae on segment viii are tufts of about four stout, subplumose hairs, which are long, the longest reaching not far short of the posterior extremities of the paddles; on segment vii small tufts of two stout, pubescent hairs; on segment vi missing, but provided with large sockets; and on segments $\mathrm{v}$ to iii delicate, simple, single hairs. The sublateral and submedian dorsal setae apparently are situated unusually near the middle line on the more anterior segments. The sublateral setae on segments vi and vii are short single hairs, and on segments iii to $\mathrm{v}$ long stout hairs reaching beyond the posterior margins of the following segments. The submedian setae on segment vii are small single hairs (on one side the hair is divided at its tip), on segments $\mathrm{v}$ and vi small double hairs, and on segments ii to iv larger triple hairs. The large tufts (fig. 14,c) on segment $i$ are of an unusual form, being stout, branched setae with a median stem giving off about fifteen subplumose hairs.

Diagnosis.-This pupa differs in some respects very notably from the other known pupae of West African species of Aëdes (Ochlerotatus), for example, in the forms of the respiratory trumpets, the paddles, and the large tufts on the first abdominal segment. Moreover, the smaller tufts on the second segment are absent, being replaced by triple (or quadruple) hairs, and in this respect, as well as in others, the pupa more closely resembles that of Aëdes (Stegomyia).

Habitat.-Accra, 15.vii.1921; one female reared from a pupa obtained from water in a rot-hole in a flamboyant tree (Poinciana regia) in the compound of a bungalow. 
Aëdes (Aëdimorphus) irritans, Theo.

LARva.-The larva has already been described (Bull. Ent. Res. vii, p. 5).

PUPA.-The pupa is of moderate size, length about $4 \mathrm{~mm}$. when extended.

Cephalothorax. The respiratory trumpets (fig. $15, a$ ) are about $0.4 \mathrm{~mm}$. long ; they are rather narrow and have small apertures. The ratio of the length of the meatus to the total length of the trumpets is about 1 to $1 \cdot 2$. The cephalothoracic setae are all small, the dorsal setae being small tufts of two or three hairs about half the length of the trumpets.

Abdomen (fig. 15). The paddles, which are nearly $0.7 \mathrm{~mm}$. long, are oval, the ratio of length to greatest breadth being about $1 \cdot 3$ to 1 ; they are supported by a well-developed midrib and a rather ill-defined external buttress. The terminal seta is single, long, nearly one-third the length of the paddle (about $0.2 \mathrm{~mm}$.), and usually slightly curved at its extremity. There is no proper fringe, but only a few denticulations along the external borders of the paddles.

The lateral setae (A) of the abdomen are highly developed only on segments vii and viii; on the other segments they are rather long and delicate single or double hairs. On segment viii they are well-developed tufts composed of from two to six subplumose hairs, the longest hairs being abous half the length of the paddles. On segment vii they are smaller tufts of two or three pubescent hairs. The sublateral setae (B) on the dorsal surface of segments iv to vi are long, reaching to about the posterior border of the following segment, single or double. The submedian setae are rather small on all segments, and are composed of one to four fine hairs. The other setae, which are mostly small, call for no special mention. In the male the cases for the claspers are very large and long.

\section{Diagnosis.-See Aëdes (Ochlerotatus) wellmani.}

Habitat.-Accra ; abundant at all times of the year in crab-holes and in collections of brackish water.

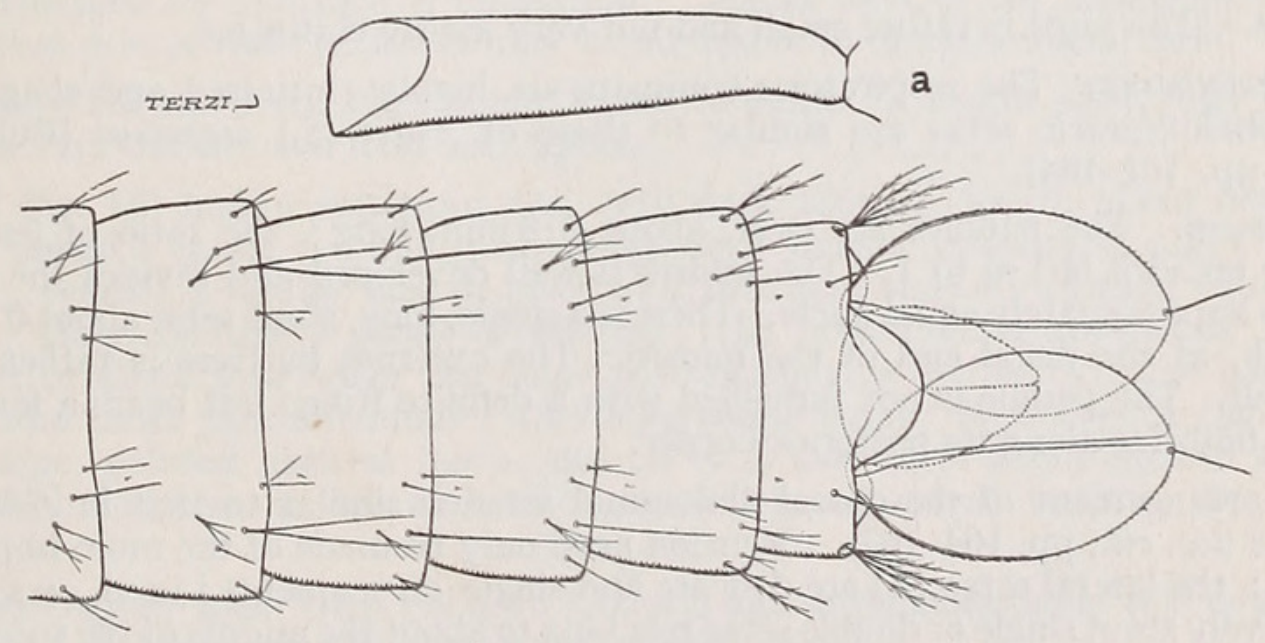

Fig. 15. Pupa of Aëdes irritans, Theo., dorsal view of abdomen : $a$, trumpet.

Aëdes (Finlaya) wellmani, Theo.

LARVA.- Head not strongly chitinised and not large relatively to the thorax. Mouth-brushes rather conspicuous. The antenna is stout and curved, with the convexity external, sparsely covered with spicules; hair-tuft situated about threeseventhis of the length of the shaft from the base, and composed of six or more subplumose hairs. The shaft of the antenna tapers gradually from the insertion of the hair-tuft to the apex. The ante-antennal tuft (outer post-antennal of Lang) 
consists of about ten to twelve subplumose hairs. The three hairs on each side of the middle line on the dorsum are large, multiple, and subplumose, the inner (preantennal) one composed of about fourteen to sixteen hairs, the posterior (inner postantennal) of five hairs, and the anterior (middle post-antennal) of six hairs. There is a large lateral hair-tuft posterior to the ante-antennal tuft consisting of subplumose hairs. The mental plate has a stout central tooth, on either side of which are ten or eleven more slender teeth, those nearest the central tooth being more closely approximated and narrower than those situated more externally.

Thorax. The thoracic plumes are fairly well developed, the constituent hairs being subplumose; the main plumes rise from chitinous bosses.

Abdomen. The dorso-lateral hairs are long, paired, subplumose. Numerous stellar hair-tufts are present on all the abdominal segments. The siphonal, subsiphonal, and anal plumes are composed of subplumose hairs. All these plumes are well developed and rise from chitinous sockets. The comb is formed of about eight pointed teeth, without secondary barbs but with a delicate fringe basally, placed in a curved row. The siphon is well chitinised, about three times as long as the diameter of its basal ring. It bears a pecten of about twenty spines which extends over rather more than one-third (five-twelfths) of its length; these spines have a secondary barb at their base and are somewhat irregularly placed. The tuft on the siphon is formed of four or five hairs, which are almost simple, and is situated at about the middle of the tube. The anal segment is irregularly chitinised over a saddle-shaped area. On each side at its posterior border is a long stout double seta. The beard is poorly developed. The dorsal hairs at the distal end of the anal segment appear to be four above and one below on each side, the latter being very long and stout. The anal papillae are well developed, about two and a half times the length of the anal segment, and have rounded extremities.

Diagnosis.-This larva may be distinguished from other known African Aëdes (Ochlerotatus) larvae by having the median hairs on the head multiple, a comb of about eight spines, and a pecten of about twenty spines.

PUPA.-The pupa is rather small and not very highly chitinised.

Cephalothorax. The respiratory trumpets are highly chitinised and shagreened. The cephalothoracic setae are similar to those of Aëdes (S.) argenteus (Bull. Ent. Res. x, pp. 161-164).

Abdomen. The paddles are oval, about $0.9 \mathrm{~mm}$. long; the ratio of length to greatest breadth is 1.6 to 1 . The midrib is well developed and divides the paddle into two approximately equal parts. There is a single, long, stout seta, about $0 \cdot 1 \mathrm{~mm}$. in length, at the distal end of the midrib. The external buttress is rather feebly developed. The paddle is not furnished with a definite fringe but bears a few short hairs or fimbriae along its posterior border.

The arrangement of the dorsal abdominal setae is similar to that in Aëdes (S.) argenteus (loc. cit., pp. 164-167). Mention need only be made of the more important of them : the lateral setae (A) are delicate and single on segments $i$ to vi, on segment vii relatively stout single or double setae reaching to about the middle of the succeeding segment, and on segment viii well developed tufts, about half the length of the paddle, composed of about six subplumose hairs, some of which are branched. The sublateral setae (B) are long and single, on segments ii and iii rather delicate, on segments iv and $\mathrm{v}$ stouter and longer and reaching backwards to about the middle of the next segment but one, on segment vi stout but rather shorter and reaching nearly to the posterior margin of the succeeding segment, and on segment vii rather stout but not reaching beyond the middle of the next segment. The dendritic tufts on segment $i$ well developed, those on the second segment smaller but characteristic. The ventral abdominal setae are small and inconspicuous and are similar to those of Aëdes (S.) argenteus (loc. cit., pp. 167-169). The abdominal stigmata are conspicuous. 
Diagnosis.-The pupae of Aëdes (O.) irritans and Aëdes (O.) wellmani fall into the group in our provisional key (Bull. Ent. Res. viii, pp. 81-82) which includes $A$. (O.) apicoanmulatus and $A$. (O.) simulans. Bacot's figure of $A$. (O.) apicoannulatus does not show any features which would distinguish this species from $A$. $(O$. irritans, since both have long (about $0.2 \mathrm{~mm}$.) terminal setae on the paddles and a fringe composed of "excessively minute and delicate" serrations, but specimens in our collection show the following differences: the dorsum of the cephalothorax and the respiratory trumpets are more deeply infuscated; the respiratory trumpets are larger, length about $0.48 \mathrm{~mm}$., and the ratio of the length of the meatus to the total length is about 1 to $1 \cdot 4$; the cephalothoracic setae are larger, the dorsal setae being large tufts of two to five hairs almost as long as the trumpets; the fringe of denticulations on the paddles is more pronounced; and the abdominal setae are more highly developed, the sublateral setae on segments iv to vi reaching fully or almost fully across the two following segments. The terminal setae on the paddles of $A$. (O.) wellmani might serve to separate this species from the other three, since they are relatively short (about $0.1 \mathrm{~mm}$.) and single. $A$. (O.) simulans, as figured by Bacot, has the terminal seta on the paddles bifid, no fringe and the lateral setae on segment vii not differentiated as tufts; but the first character may be variable (as it is in some other species), and as regards the other two the figures may be misleading owing to the relatively low magnification at which they are drawn. Bacot's figures are not sufficiently detailed to show the sublateral and submedian setae, which may furnish additional, and perhaps more satisfactory, differential points.

Habitat.-Aburi, from the hollow in the stem of a cut bamboo, 6.vi.1920.

\section{Aëdes (Finlaya) longipalpis, Grünb.}

Wesché (Bull. Ent. Res. i, pp. 29-30) described the larva of this mosquito under the name Stegomyia pollinctor, Graham, but he had at his disposal only a single damaged specimen, and, as noted by Edwards, the description given is insufficient for identification. Edwards states also that "the specimens in the British Museum are too damaged for purposes of tabulation." As we have in our possession a larva and a larval pelt of this species, it may be advisable to describe them here.

LARVA.-The larva measures about $5 \mathrm{~mm}$. to $6 \mathrm{~mm}$. in length when fully grown, and has a very dark brown head and siphon.

Head (fig. 16) highly chitinised and very dark brown; length about $0.8 \mathrm{~mm}$., greatest breadth about $1.1 \mathrm{~mm}$. Antennae dark brown, cylindrical, short (about $0.3 \mathrm{~mm}$.), bearing a double hair in place of a tuft, and sparsely clothed with small spicules. Hairs relatively poorly developed; the pre-antennal apparently a very small tuft of about four hairs, the outer post-antennal a double or triple hair, and the mid and inner post-antennals rather long single hairs. Mental plate (fig. 16,a) with a large, pointed, central tooth, and on each side of it about sixteen smaller teeth, which increase in size and are more widely separated towards the lateral margin.

Thorax slightly wider than the head; lateral hair-tufts moderately well developed and without definite spine-like processes at their bases.

Abdomen not very hairy. Dorso-lateral hairs well developed on the first two segments only. Siphonal (fig. 16) and anal tufts small, composed of about five delicate, apparently simple, hairs ; subsiphonal tuft larger, composed of about five plumose hairs. Comb a roughly triangular patch of very numerous ( ? about 100) small fringed scales. Siphon very dark brown, tapering distally and slightly constricted at its base; length about four times the basal diameter. Pecten a row of about seventeen long pointed spines with small basal barbs, reaching to about the middle of the siphon, without detached spines. Hair-tuft composed of about eight delicate hairs, situated a little beyond the end of the pecten. Anal segment slightly 
longer than broad; chitinised area saddle-shaped, bearing at its posterior margin a few spicules and a tuft of delicate hairs. Beard moderately well developed. Dorsal hairs at the posterior margin of the anal segment long, four or five above and one below on each side. Anal papillae described by Wesché as unequal, the dorsal pair twice the size of the ventral; in our specimens the dorsal pair are apparently atrophied.

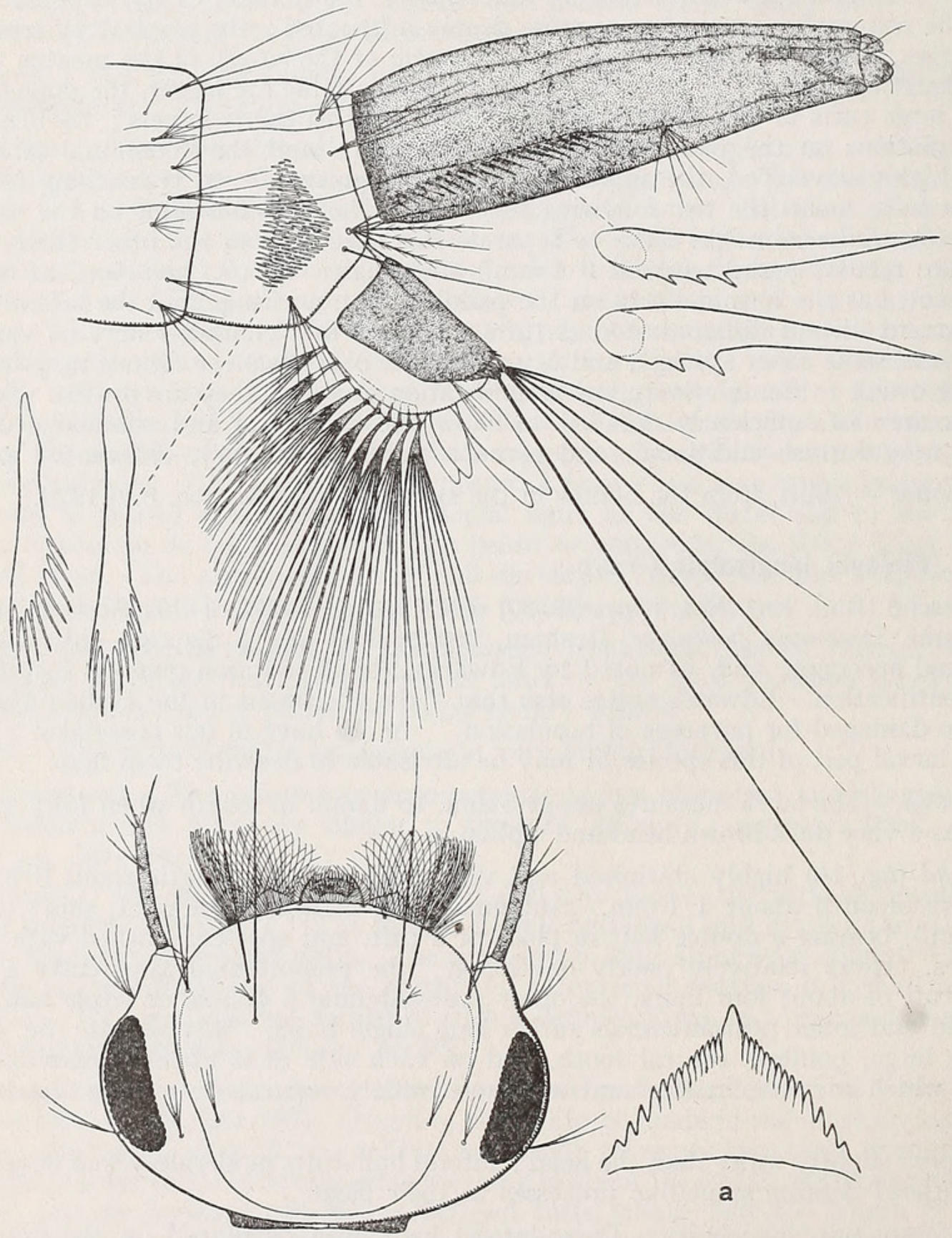

Fig. 16. Larva of Aëdes longipalpis, Grünb., head and terminal segments of abdomen : $a$, mental plate.

Diagnosis. - This larva according to Edwards's key (Bull. Ent. Res. iii, p. 376) has to be distinguished from those of Aëdes (O.) nigeriensis and Aëdes (S.) vittata, which also have the median hairs on the head single. From both these it may be separated, to mention only one of many characters, by the number of scales in the comb. 
PupA.-The pupa is about $5 \mathrm{~mm}$. long when extended.

Cephalothorax somewhat infuscated dorsally and posteriorly. Respiratory trumpets (fig. 17, a) very dark brown, short, length about $0.5 \mathrm{~mm}$., straight, with a rather small, slightly constricted aperture ; ratio of length of meatus to total length about 1 to $1 \cdot 2$. Cephalothoracic setae well developed, the dorsal setae rather large tufts of three to six pubescent hairs, about as long as the respiratory trumpets.

Abdomen. Paddles (fig. 17) more or less pyriform, small; length usually about $0.4 \mathrm{~mm}$. (in one specimen $0.7 \mathrm{~mm}$.), ratio of length to greatest breadth about 1.2 to 1. Midrib and external buttress moderately developed; fringe represented only by minute denticulations. Terminal seta at the end of the midrib usually about one-quarter the length of the paddles (i.e., about $0.1 \mathrm{~mm}$.), and not bifid-in one very large female, however, it was longer, over one-third the length of the paddles.

Dorsal abdominal setae (fig. 17) well developed. Lateral setae (A) on segment viii large tufts, more than half the length of the paddles, composed of about ten or eleven subplumose hairs, on segment vii small tufts of two or three hairs, and on segments iii to vi delicate hairs, usually single but sometimes double or triple. Sublateral setae (B) on segment vii small hairs subdivided at the ends, on segments iv to vi long, single or double, pubescent setae which extend backwards slightly beyond the posterior margins of the following segments. Submedian setae (C) on segments iv to vii delicate tufts of usually four hairs, which are rather larger on the more anterior segments; on segment iii the corresponding seta is also a delicate tuft, rather smaller than that on segment iv, but with more branches, usually about nine. The dendritic tufts on segment $i$ are large and composed of long subplumose hairs, which are branched mainly at their ends; the tufts on segment ii are rather large, with numerous branches - in the very large female referred to before, the tufts on segment i were practically unbranched, and those on segment ii (as shown in fig. 17) composed of only four or five long unbranched hairs. In the male the cases for the claspers are very large and reach almost to the posterior margins of the paddles.

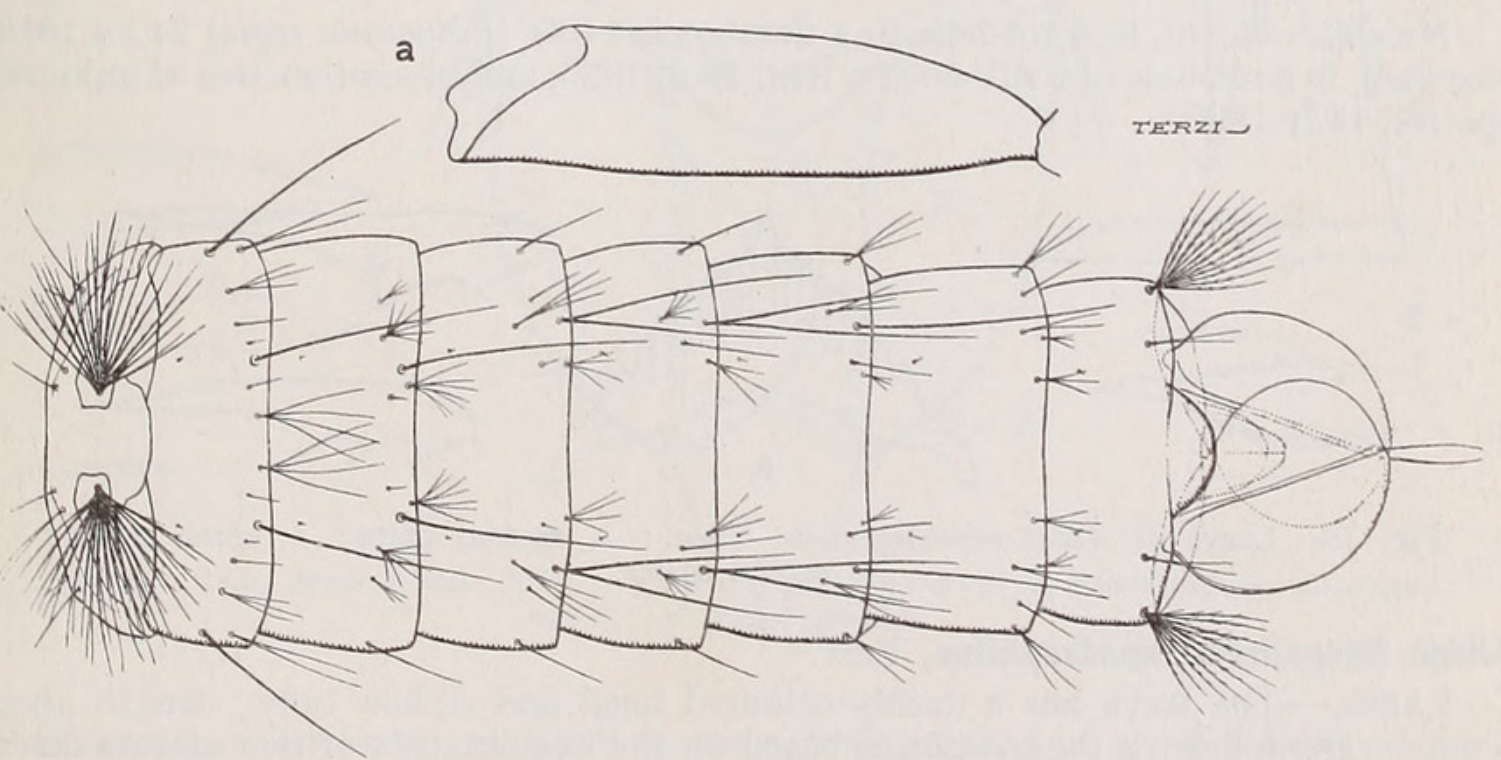

Fig. 17. Pupa of Aëdes longipalpis, Grünb., dorsal view of abdomen : a, trumpet.

Diagnosis.-This pupa falls into the same group as those of Aëdes (O.) irritans, $A$. (O.) rellmani, $A$. (O.) apicoanmulatus, and $A$. (O.) simulans, the differential characters of which cannot be given with certainty until further material has been examined to determine the range of variations in the several species. The following 
points, which appear to provide distinguishing features, may however be mentioned ; in $A$. (O.) simulans, according to Bacot, the terminal seta on the paddles is bifid; in $A$. (O.) wellmani the paddles are longer and narrower, and the terminal seta on them is relatively shorter; in $A$. (O.) apicoanmulatus the sublateral setae on the dorsum of segments iv to vi of the abdomen are longer; and in $A$. (O.) irritans the paddles are larger, the respiratory trumpets shorter, and the dorsal setae on the cephalothorax smaller tufts.

Habitat.-Ofako, a village about nine miles north of Accra on the Nsawam road, v.-vi. 1922 ; larvae found in a rot-hole in a tree in dense " bush." In the same rot-hole were found larvae of Megarhimus (Toxorhynchites) brevipalpis, Aëdes (O.) apicoanmulatus, and C. (Culiciomyia) macfiei, Edw., a new species of which the description is published above (p. 399).

\section{Aëdes (Stegomyia) apicoargenteus, Theo.}

LARva.-The larva resembles that of $A$. (S.) dendrophilus, but the following differences may be noted. The siphon is perhaps a little shorter, length about twice the basal width, and its apical fourth is paler than the basal three-quarters. The pecten extends in a somewhat curved line for from one-third to nearly one-half the length of the siphon and is composed of about twelve to sixteen spines, which have long sharp points and well-developed basal barbs (fig. 18,c). The tuft on the siphon is situated just beyond the last spine of the pecten and is usually double, occasionally single or triple. The hair on each side of the anal segment near the middle of the posterior margin is long, and in all the specimens examined by us, single. The larva also closely resembles that of $A$. (S.) luteocephalus, and although there are several characters usually unlike-such as the long hair on the siphon in place of a tuft-none of them was constantly different.

PupA.-The pupa also resembles that of $A$. (S.) dendrophilus, indeed we were unable to find any points of constant difference. From the pupa of $A$. (S.) luteocephalus, however, it differs in several particulars, notably in the development of the fringe on the paddles.

Habitat.-Accra, in a rot-hole in a flamboyant tree (Poinciana regia) 24.xii.1918; Nsawam, in a rot-hole of a silk-cotton tree, 26.iii.1920, and in another tree of unknown species, 14.iv.1920.
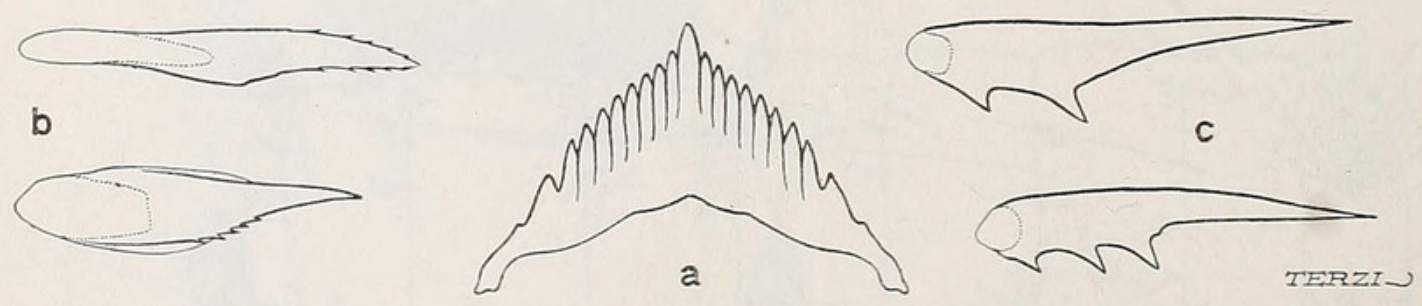

Fig. 18. Larva of Aëdes apicoargenteus, Theo.: $a$, mental plate; $b$, comb scales; $c$, pecten scales.

Aëdes (Stegomyia) dendrophilus, Edw.

LARVA.- The larva has a darkly-coloured head and siphon tube: length about $5 \mathrm{~mm}$. The following description is based on the examination of two mature larvae and six larval pelts.

Head strongly chitinised, dark-coloured ; in mature specimens length and greatest breadth about equal $(0.7 \mathrm{~mm}$.). Antennae dark, especially at the base, not covered with spicules, and bearing a single small hair in place of a tuft, length about $0.3 \mathrm{~mm}$. Mid-frontal hairs single, long and slender. Eyes large and well-formed. Mental plate (fig. 19, a) rather short and broad, with a median tooth and nine to twelve smaller teeth on each side. 
Thorax broad, about $1 \mathrm{~mm}$. in mature specimens, moderately well clothed with hairs, spines not very highly developed.

Abdomen only moderately hairy, bearing numerous small single, double and triple hairs, and long double lateral hairs which are well developed, especially on the anterior segments. Comb composed of about ten spines set in a transverse row, the spines highly chitinised, sharply pointed-but the extreme tip frequently broken off-and with very small secondary barbs hardly visible, except with high powers of the microscope (fig. 19, b). The siphonal tuft is triple, the subsiphonal composed of five hairs, and the anal of triple hairs; all the hairs simple or very slightly pubescent. Siphon very dark-coloured, length nearly three times the basal width (about $0.7 \mathrm{~mm}$. to $0.25 \mathrm{~mm}$.). The pecten extends half the length of the siphon or further and is composed of about eleven to thirteen spines, the last one or two sometimes outlying; the spines are sharply pointed and with very small secondary barbs hardly visible without the aid of high objectives of the microscope (fig. 19, c). The siphon tuft lies just beyond the last spine of the pecten and is composed of a single or double stout hair ; when there are outlying pecten spines the tuft is proximal to them and thus appears to lie in the line of the pecten. Anal segment short. Papillae long and broad, with rounded ends ; all four equal in length and longer than the anal segment. Beard poorly developed. Dorsal hairs well developed, two or three above and one below on each side. On each side of the anal segment, near the middle of its posterior margin, is a long single or more usually double hair.
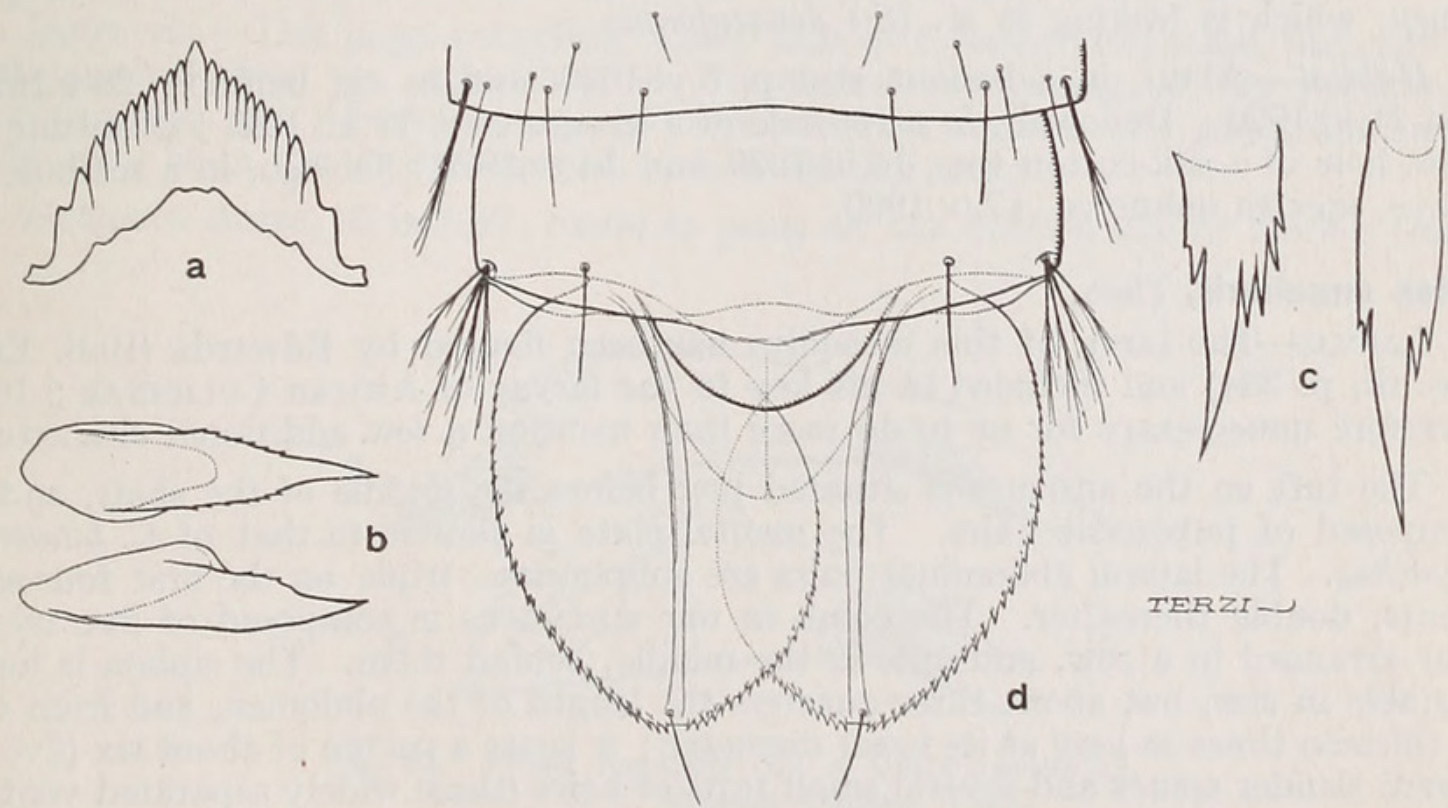

Fig. 19. Aëdes dendrophilus, Edw. : $a$, mental plate of larva ; $b$, comb scales ; $c$, pecten scales; $d$, pupal paddles.

Diagnosis.-The larva resembles in some respects that of $A$. (S.) luteocephalus, but may be distinguished from it by the characters of the scales of the pecten. It may be noted in this connection with regard to $A$. (S.) luteocephalus that the hook-like spines on the thorax are generally rather less well developed than those of $A$. $(S)$. argenteus and rather better developed than those of $A$. (S.) dendrophilus; that the comb-scales when highly magnified are seen to be finely fringed; that the siphonal and subsiphonal tufts when similarly magnified are seen to be slightly subplumose and more so than those of $A$. (S.) dendrophilus; and that the hair on the siphon representing the tuft is sometimes divided, although usually single. 
PupA.-The pupa is of moderate size, measuring about $4 \mathrm{~mm}$. to $5 \mathrm{~mm}$. when extended, and is well chitinised. The following description is based on the examination of ten specimens. The paddles (fig. 19, d), which average about $0.7 \mathrm{~mm}$. in length, are rather narrow, narrower than those of $A$. (S.) argenteus, and in both sexes are somewhat pointed at the distal extremity, the ratio of their length to their greatest breadth averaged 1.4 to 1 . They are supported by a broad, highly chitinised, midrib, but there is little if any trace of an external buttress. The seta at the distal end of the midrib is usually single, occasionally double or bifid, it is long, average length about $115 \mu$. The paddles bear a short fringe of somewhat denticulate processes. The chaetotaxy of the pupa is similar to that of $A$. (S.) argenteus. The lateral setae (A) at the posterior angles of segment viii are not very large tufts, which are somewhat variable; in the ten specimens examined they were composed of from two to eight setae, average four, which were sometimes simple, sometimes subplumose, sometimes branched. On segment vii these tufts are poorly developed and are generally represented by a single stout seta which is usually simple but may be subdivided into two or three branches and may be subplumose. The lateral setae on the sixth and more anterior segments are quite small, single and simple. The other setae of the pupa do not call for special mention as they are apparently similar to those of $A$. (S.) argenteus; they are, however, rather small and usually single.

Diagnosis.-The most characteristic feature of the pupa is the shape of the paddle, which distinguishes it from the other species, except $A$. (S.) apicoargenteus, that we have examined. It should, however, be noted that the pupal paddles of the male of $A$. (S.) luteocephalus are of the same shape, but they have a well-developed fringe, which is lacking in $A$. (S.) dendrophilus.

Habitat.-Aburi, in a banana stump, 6.vi.1920, and in cut bamboo, 26.v.1920, and 21.xi.1920 ; Dodowah, in a rot-hole of a mango tree, 17.xii.1921 ; Nsawam, in a rot-hole of a silk-cotton tree, 16 iii.1920 and 14.iv.1920; Oblogo, in a rot-hole of a tree, species unknown, 17.iv.1920.

\section{Culex annulioris, Theo.}

LARVA.- The larva of this mosquito has been figured by Edwards (Bull. Ent. Res. iii, p. 384) and included in his key to the larvae of African CulicinaE; it is therefore unnecessary for us to do more than mention a few. additional characters.

The tuft on the antenna is situated just before the middle of the shaft, and is composed of pubescent hairs. The mental plate is similar to that of $C$. bitaeniorhynchus. The lateral abdominal hairs are subplumose, triple on the first four segments, double thereafter. The comb in our specimens is composed of five teeth, four arranged in a row, and one, in the middle, behind them. The siphon is long, variable in size, but about three-quarters the length of the abdomen, and from ten to thirteen times as long as its basal diameter; it bears a pecten of about six (five to seven) slender spines and several small tufts of hairs (three widely separated ventral tufts and a pair of subapical tufts). The anal segment is rather long and narrow and bears a moderately well-developed beard. The dorsal hairs on the anal segment are three or four above and one below on each side. The anal papillae are long, slightly longer than the anal segment, subequal, and bluntly pointed at their extremities.

Diagnosis. - This larva resembles that of $C$. bitaeniorhynchus but may be distinguished from it by the number of pecten spines, which is about six instead of only three.

PupA.-The pupa is large, and has infuscated paddles. Only a single pelt was examined.

Cephalothorax. The respiratory trumpets (fig. 20,a) are long and rather narrow, and in the living pupa are directed forwards; they are rather pointed at their tips, have not very wide openings, and are infuscated at the distal end and over a patch 
a short distance above the base. They are about $1.1 \mathrm{~mm}$. long, and the ratio of the length of the meatus to the total length is about 1 to $1 \cdot 3$. The cephalothoracic setae are mostly small and inconspicuous, but the internal postero-thoracic seta is a rather conspicuous tuft of about six subplumose hairs.

Abdomen. The paddles are infuscated and very broad; length about $1.0 \mathrm{~mm}$., greatest breadth about $0.85 \mathrm{~mm}$. The midrib and external buttress are moderately well developed, the latter extending more than half the length of the paddles. The infuscation is most marked at the distal end and to the inner side of the midrib. The hairs at the end of the midrib are two, both very small $(25 \mu$ to $30 \mu)$, but the one stouter than the other and subdivided at its end. There is no fringe, but the external buttress bears a few minute denticules.

The abdominal setae are generally similar to those of Culex bitaeniorhynchus. The lateral setae on segment viii are small tufts, about one-quarter the length of the paddle, composed of five stout, subplumose hairs ; on segment vii similar tufts of three hairs; on segments vi and $\mathrm{v}$ long $(0.4 \mathrm{~mm}$.), stout, single setae; and on segment iv reduced to shorter, delicate, single setae. The sublateral setae on the dorsum on segments vi and $\mathrm{v}$ are long, strong, double setae reaching right across the succeeding segment; on segment vii single, more delicate and smaller, reaching only about half-way across the eighth segment; on segment iv tufts of three long hairs. The submedian setae increase in size from behind forwards; on segments vii and vi they are single hairs; on segments $\mathrm{v}$, iv and iii tufts of two to three, four to five, and about seven hairs respectively. The dendritic tufts on segment $\mathrm{i}$ are well developed. The other abdominal setae do not call for special mention.

Diagnosis. - This pupa resembles closely that of $C$. bitaeniorhynchus, but may be distinguished from it, apparently, by the narrower opening of the respiratory trumpets (fig. 20). Further material is required to confirm any small differences there may be in the cephalothoracic and abdominal setae.

Habitat.-Accra, 26.ix.1921, found in pools on the western side of Korley Gona.

a

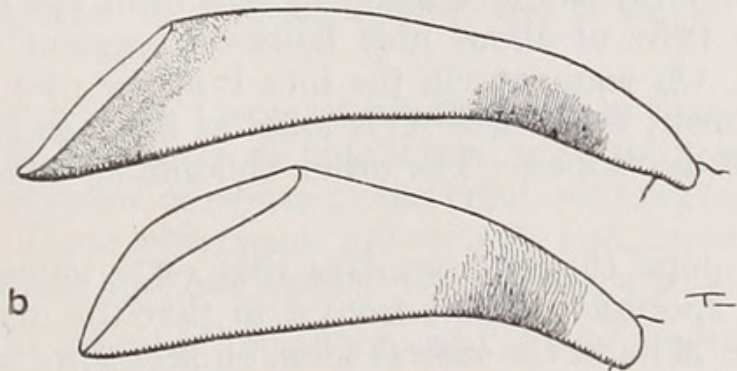

Fig. 20. Pupal trumpets of: $a$, Culex annulioris, Theo.; $b, C$. bitaeniorhynchus, Theo.

Culex ingrami, Edw.

LARva.-The larva of this mosquito has already been described (Bull. Ent. Res. vii, pp. 11-12).

PuPA.-The pupa, of which only a single specimen was examined, is rather feebly chitinised and has long slender respiratory trumpets (fig. 21, a) and long sublateral setae on the dorsal aspect of the fifth and sixth abdominal segments.

Cephalothorax. The respiratory trumpets are long and slender tubes with an infuscated band a little above their bases, and with narrow apertures. Their length is about $0.6 \mathrm{~mm}$., their width in the middle about $95 \mu$, and the length of the apertures (pinna) about $93 \mu$; the ratio of the length of the meatus to the total length is nearly 
1 to $1 \cdot 2$. The cephalothoracic setae are small and call for no special mention; but the postero-thoracic setae are moderately well developed, the internal being composed of about half a dozen hairs, and the other two apparently each of two hairs.

Abdomen. The paddles are of moderate size and are relatively broad; length about $0.7 \mathrm{~mm}$., greatest breadth about $0.5 \mathrm{~mm}$. The external buttress is poorly developed and denticulated. The midrib is well developed. The hairs at the distal end of the midrib are two, single, both very small and measuring about $50 \mu$ and $25 \mu$ in length respectively. There is no fringe.

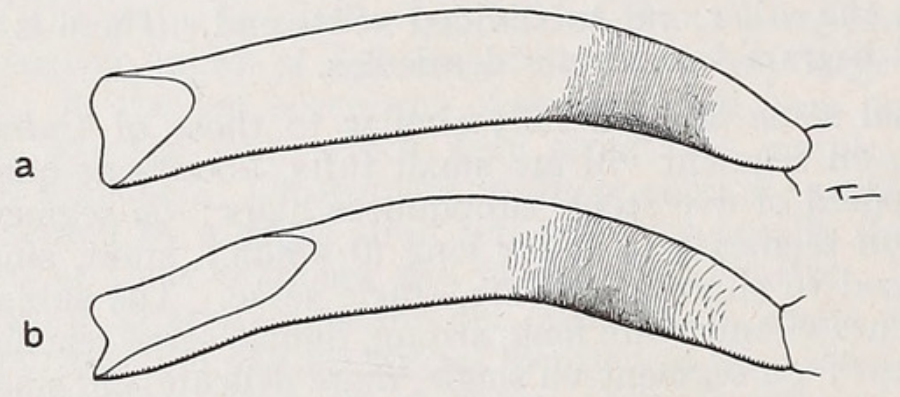

Fig. 21. Pupal trumpets of : a, Culex ingrami, Edw. ; $b, C$. decens, Theo.

The abdominal setae are similar to those of $C$. decens. The lateral setae on segment viii are tufts, rather more than one-quarter the length of the paddles, composed of eight or nine rather stout subplumose hairs, some of which are branched ; on segment vii similar but rather smaller tufts of five hairs, which are also subplumose and usually branched; on segments iii to vi delicate tufts of five simple slender hairs. The sublateral dorsal setae on segments $\mathrm{v}$ and vi are long, double (but one branch subdivided on one side of segment $\mathrm{v}$ ) hairs reaching a little beyond the posterior margin of the following segment; on segment vii short single or double hairs ; and on segment iv long quadruple hairs reaching right across the following segment. The submedian setae are tufts increasing in size from small tufts of four hairs on segment vii to large tufts of about nine hairs on segment iv and of about fifteen hairs on segment iii. On segment viii the seta $\mathrm{P}$ at the root of the paddle is slender and double. On segment ii the seta $\mathrm{A}^{\prime}$ is long, as in $C$. decens. The dendritic tufts on segment $\mathrm{i}$ are well developed. The other abdominal setae do not call for special mention.

Diagnosis.-This pupa closely resembles that of $C$. decens, but so far as can be judged from a single specimen, differs from it in that the respiratory trumpets have smaller apertures (fig. 21) and the lateral setae on segments iii to $\mathrm{v}$ have rather more hairs. It resembles also the pupae of $C$. guiarti and $C$. grahami, the most notable difference being, perhaps, in the length of the sublateral setae on segments $\mathrm{v}$ and vi, which are rather longer than one abdominal segment, but not as long (or nearly as long) as two, as they are in these two species.

Habitat.-Near Dodowah, 14.i.1922, in a small pool in a borrow-pit close to a native village.

Culex grahami, Theo.

LARVA.-The larva of this mosquito, which was described by Wesché (Bull. Ent. Res. i, p. 46) under the name $C$. pullatus, Graham, is re-described here in rather greater detail in order that a comparison may be made with the larva of $C$. guiarti, Blanch. The larva is about $4.5 \mathrm{~mm}$. in length when fully grown, and has a very long siphon (over $3 \mathrm{~mm}$.). In water it rests with the siphon nearly vertical and the body almost at a right angle to it, and with the head bent downwards. 
Head large but not highly chitinised; length about $0.9 \mathrm{~mm}$., greatest breadth about $1.3 \mathrm{~mm}$. Antenna slightly curved and bearing at about two-thirds of its length a large tuft of plumose hairs. The portion of the shaft distal to the tuft is very dark-coloured and highly chitinised. There are numerous spicules on the shaft, those on the pale basal portion slender, those on the dark apical portion stouter. At the end of the antenna are three long, stout, dark hairs which are simple, and not pubescent as they are in $C$. guiarti, a short spine-like dark hair with smaller spines at its base, and a small, less highly chitinised cylindrical organ, which apparently is the "spine" that Wesché notes as being "very liable to injury." The post-antennal hairs (to use the terms employed by Lang) are well-developed tufts of plumose hairs, the outer composed of about a dozen hairs, the longest of which extend beyond the middle of the antenna, the middle composed of two or three and the inner of three to five hairs. In C. guiarti the middle and inner tufts are each composed of two hairs. The mental plate has a large, rather bluntly-pointed central tooth, with a closely applied small tooth and more externally five more widely separated teeth on each side.

Thorax not so wide as the head; it has well developed lateral tufts of plumose or subplumose hairs and long hairs projecting over the head.

Abdomen. The lateral abdominal hairs appear to be triple on all the segments but are strongly developed on the first two segments only. Curious dendritic tufts, most strongly developed on the posterior segments, are also present. The siphonal, subsiphonal and anal tufts are well developed, the hairs composing the two first being plumose, those composing the last apparently pubescent or simple. The comb is made up of about fourteen to twenty pointed and fringed scales arranged in an irregular patch. The siphon is about twelve to fourteen times as long as the diameter of its base, tapering slightly in the basal quarter but thereafter almost uniformly cylindrical. The pecten is composed of six to nine simple spines confined to the basal seventh of the siphon. Distal to the pecten are several pairs of very delicate small hair-tufts, each composed of two or three hairs. Anal segment slightly longer than broad with papillae equal, long, slender, and pointed at their extremities, exceeding the anal segment slightly in length. The beard is moderately well developed, its constituent hairs rather longer than the papillae. Dorsal hairs at the posterior margin of the anal segment four to six above and a single longer hair below on each side.

Diagnosis.-This larva bears a general resemblance to that of C. guiarti, but may be distinguished from it by numerous characters, such as those of the post-antennal hairs on the head, the number of spines in the comb and pecten and the dorsal hairs on the anal segment. These differences are notable and appear to indicate that the two mosquitos are distinct and not merely varieties of a single species.

PUPA.-The pupa is greenish in colour, and resembles that of $C$. guiarti, but is more highly chitinised.

Cephalothorax. The respiratory trumpets (fig. 22,a) are long and slender, their basal halves dark and highly chitinised, and their distal ends with narrow apertures. Their length is about $0.85 \mathrm{~mm}$. and the ratio of the length of the meatus to the total length of the trumpet is about 1 to $1 \cdot 1$. The cephalothoracic setae are mostly inconspicuous and call for no special comment. The postero-thoracic setae, however, are small, each composed of two hairs, whereas in C. guiarti apparently the internal one is composed of about five and the external of three hairs.

Abdomen (fig. 22,b). The paddles are of moderate size, length about $0.8 \mathrm{~mm}$., greatest breadth about $0.6 \mathrm{~mm}$. The external buttress is rather slender and is denticulated, the midrib being somewhat more substantial. There is no fringe. The hairs at the distal extremity of the midrib are very small. The abdominal setae are similar to those of $C$. guiarti. The lateral setae on segment viii are small tufts, about one-quarter to one-third of the length of the paddles, composed of seven to nine 
hairs; on segment vii are similar tufts of five or six hairs; on segments iii to vi are delicate tufts composed of three to five hairs. The sublateral dorsal setae on segments $\mathrm{v}$ and vi are long double hairs reaching nearly across the two following segments ; on segment vii is a much shorter hair ; and on segment iv a long, usually triple hair (quadruple in the specimen figured) reaching across the following segment and often half of the one beyond that. The submedian setae are tufts increasing in size from a small tuft of two or three hairs on segment vii to a larger tuft on segments iii and iv composed of ten to sixteen and ten or eleven hairs respectively. On segment viii the seta $(\mathrm{P})$ at the root of the paddle is slender and double. On segment ii the seta $\left(\mathrm{A}^{\prime}\right)$ is, as in $C$. guiarti, very long and single. The dendritic tuft on segment $\mathrm{i}$ is well developed.

Diagnosis.-This pupa resembles closely that of $C$. guiarti, but appears to be more robust and is generally more heavily chitinised. It may be distinguished from it, to mention only one character, by the sublateral setae on segment iv, which are long, usually triple hairs reaching across the following segment and not shorter tufts of about five hairs.

Habitat.-Accra, 26.ix.1921, a single larva collected in a pool on the western side of Korley Gona ; Ofako, a village about nine miles north of Accra, on the Nsawam road, 5.vi.1922, larvae found in a pool in a swamp ; in the same pool were also larvae of Anopheles marshalli.

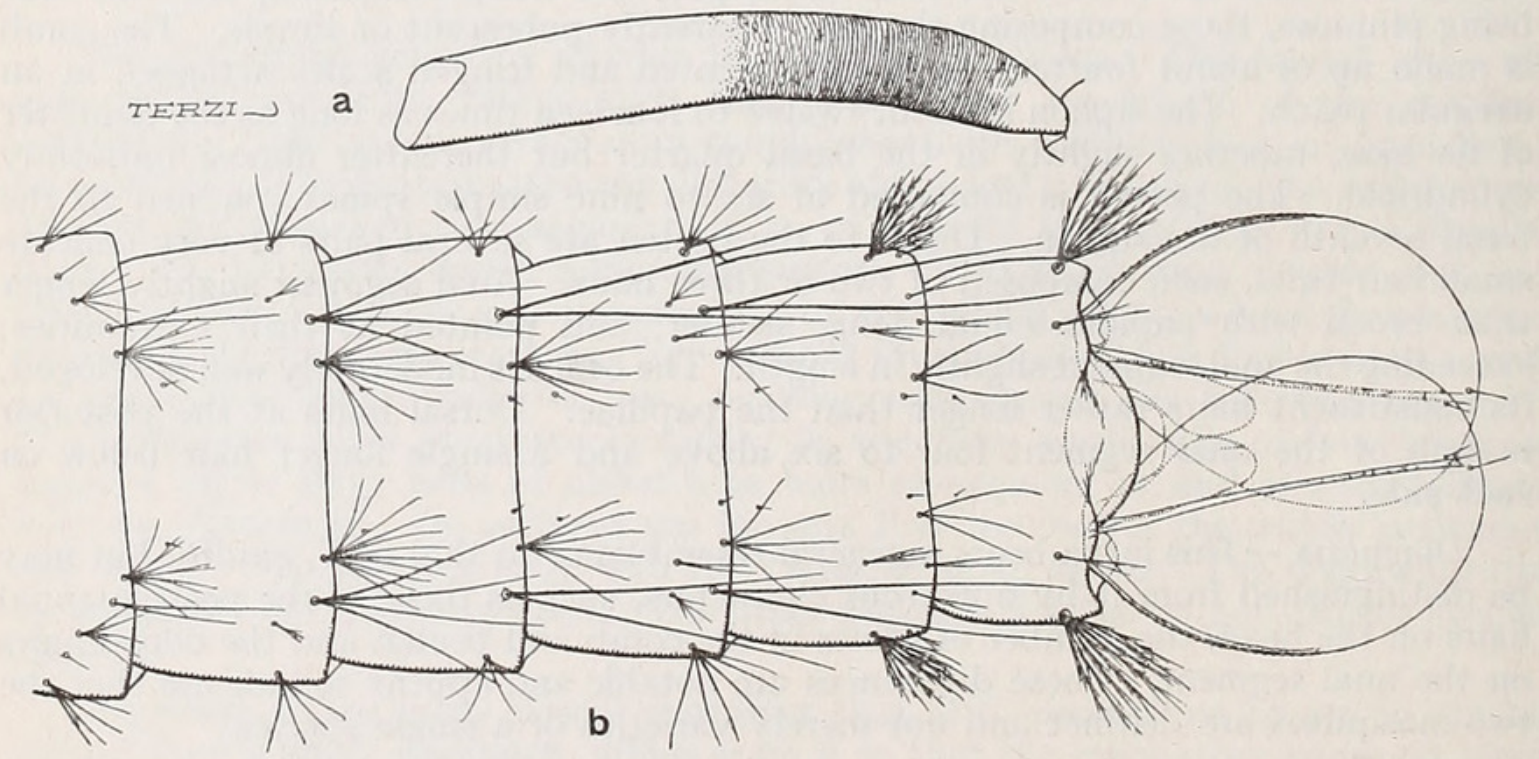

Fig. 22. Pupa of Culex grahami, Theo. : $a$, trumpet; $b$, dorsal view of abdomen.

\section{Culex (Culiciomyia) macfiei, Edw.}

LARva.-Length about $4 \mathrm{~mm}$. when fully grown; siphon long, about $1.3 \mathrm{~mm}$., and dark brown.

Head (fig. 23) large, almost as broad as the thorax, not very highly chitinised, length about $0.8 \mathrm{~mm}$., greatest breadth about $0.9 \mathrm{~mm}$. Eyes large, situated at the broadest part of the head. Antennae about $0.4 \mathrm{~mm}$. long, slightly curved, a little infuscated, especially at the ends, spiculated over the basal two-thirds, and bearing a well-developed tuft of subplumose hairs at about three-quarters of the length from the base. The pre-antennal hair of Lang is a small, simple, single hair, the outer post-antennal a well developed tuft of about eight subplumose hairs, the mid postantennal a long, double, subplumose hair, and the inner post-antennal a similar long hair, which is triple. Mental plate (fig. 23, a) rather small, with a large, pointed, central tooth and about nine smaller teeth on each side of it. 
Thorax broad; length about $0.8 \mathrm{~mm}$., greatest breadth about $1 \mathrm{~mm}$. The setae on the anterior border are long, longer than the head. The lateral tufts are well developed.

Abdomen with long lateral tufts on the first two segments, and thereafter shorter, double, dorso-lateral hairs. Comb (fig. 23) composed of about thirty-six small, dark, fringed spines arranged in a triangular patch. The siphonal tuft small, composed of about four rather stout subplumose hairs ; the subsiphonal longer, composed of about eight subplumose hairs; the anal small, double, pubescent. The siphon (fig. 23) is very dark brown, long, length about eight times the basal diameter, tapering only slightly, and bearing on its distal two-thirds three or four pairs of tufts composed of three or four rather long pubescent hairs. Pecten composed of about

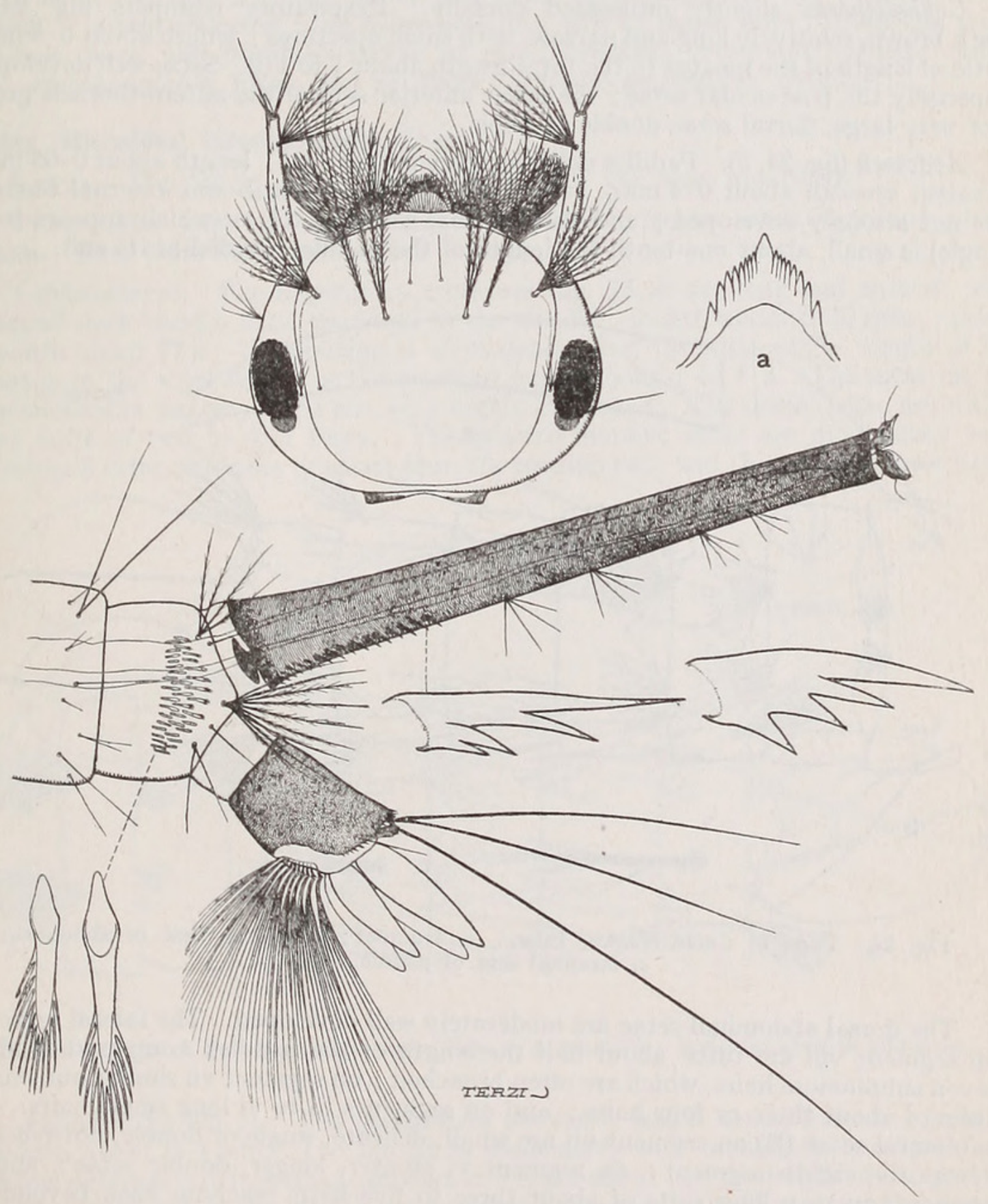

Fig. 23. Larva of Culex macfiei, Edw., head and terminal segments of abdomen : $a$, mental plate. 
fourteen to sixteen pointed, barbed spines, arranged in a row which reaches about one-third of the length of the siphon from its base. Anal segment longer than broad, the chitinised part very dark brown, covered by short transverse rows of spicules, the posterior margin bearing on each side a few small spines and a small single hair. Beard well developed. Dorsal setae long; two above and one below on each side. Anal papillae short, pointed, the dorsal pair longer than the ventral.

Diagnosis.-According to Edwards's key (Bull. Ent. Res. iii, p. 381) this larva has to be distinguished from that of Culex decens. Theo. ; this is readily done by the tufts of hairs on the siphon, to mention only a single character.

PUPA.-The pupa is small, length about $4 \mathrm{~mm}$. when extended, and not very highly chitinised.

Cephalothorax slightly infuscated dorsally. Respiratory trumpets (fig. 24, a) dark brown, relatively long and narrow, with small apertures ; length about $0.5 \mathrm{~mm}$., ratio of length of the meatus to the total length about 1 to $1 \cdot 2$. Setae well developed, especially the post-ocular setae; the lower anterior seta of the antero-thoracic group not very large, dorsal setae double or triple.

Abdomen (fig. 24,b). Paddles delicate, more or less oval ; length about $0.65 \mathrm{~mm}$., greatest breadth about $0.4 \mathrm{~mm}$., ratio 1.6 to 1 . The midrib and external buttress are not strongly developed; and the terminal seta (fig. 24, c) (which appears to be single) is small, about one-tenth the length of the paddle, divided at its end.

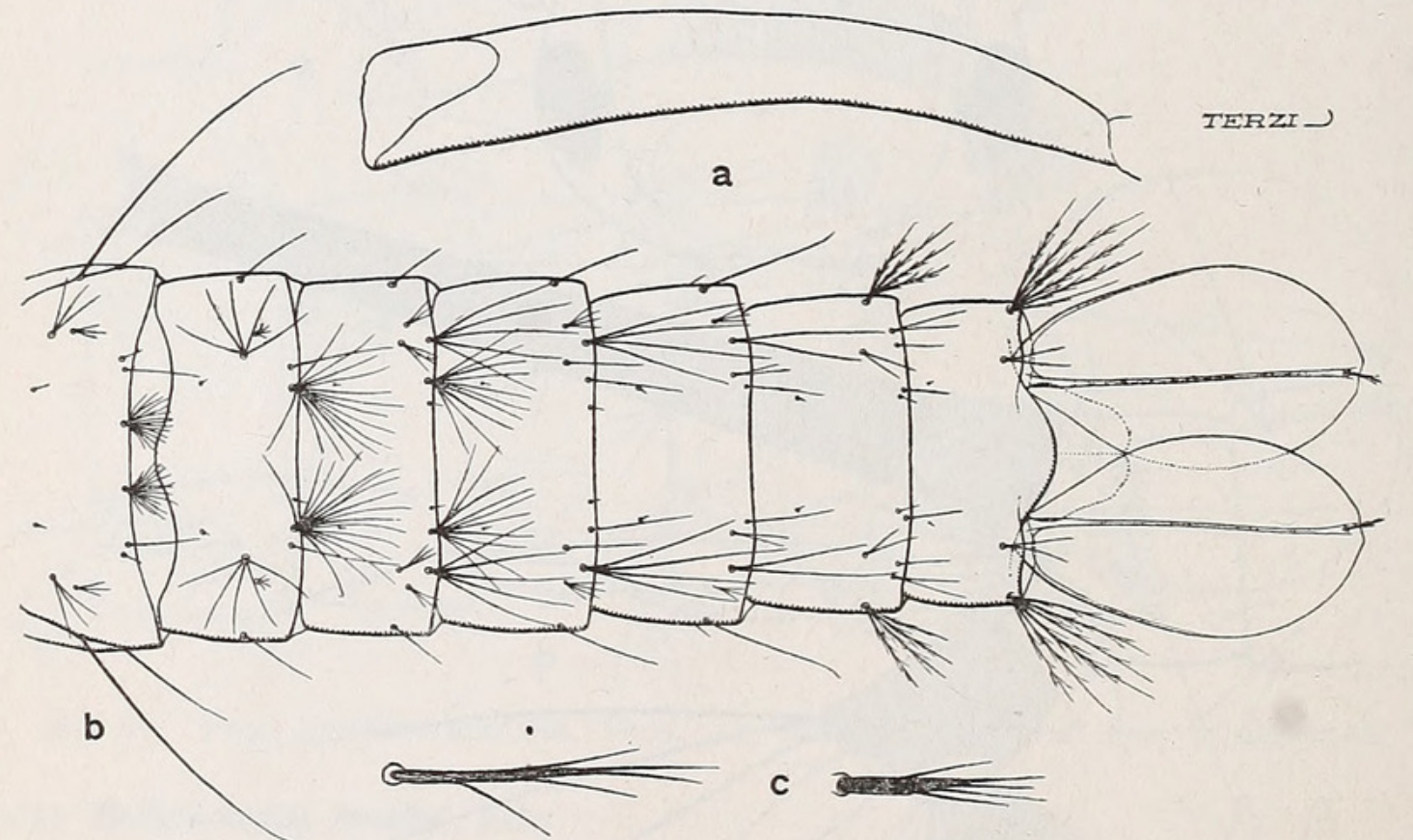

Fig. 24. Pupa of Culex macfiei, Edw. : $a$, trumpet; $b$, dorsal view of abdomen ; $c$, terminal seta of paddle.

The dorsal abdominal setae are moderately well developed. The lateral setae (A) on segment viii are tufts about half the length of the paddles composed of about seven subplumose hairs, which are often branched; on segment vii similar but smaller tufts of about three or four hairs ; and on segments iii to vi long single hairs. The sublateral setae (B) on segment vii are small, delicate, single or double, not reaching across the eighth segment; on segment vi stouter, longer, double setae; and on segments iv to $\mathrm{v}$ long tufts of about three to five hairs reaching back beyond the posterior margin of the following segment; these setae are slightly subplumose or pubescent. The submedian setae (C) on segments $\mathrm{v}$ to vij are delicate, single or 
double hairs reaching about half across the following segment, on segments iii to iv larger, delicate tufts, the former composed of about fifteen to seventeen and the latter of about seven to nine slightly subplumose hairs. The dendritic tufts on segment $\mathrm{i}$ are large and greatly branched; those on segment ii are smaller but relatively well developed.

Diagnosis.-This pupa is quite unlike that of $C$. decens, Theo., and may readily be distinguished by the characters of the chief abdominal setae. As has already been mentioned the lower seta of the antero-thoracic group on the cephalothorax is not exceptionally large, as it is in Culiciomyia nebulosa, Theo. The adult of this species, which is new to science, is described above (p. 399).

Habitat.-Ofako, a village about nine miles from Accra, on the Nsawam road, v.1922 ; larvae collected from a rot-hole in a tree in dense bush; from the same rot-hole were also obtained larvae of Toxorhynchites brevipalpis, Theo., Aëdes (O). apicoanmulatus, Edw., and of Aëdes (Finlaya) longipalpis, Grünb.

\section{Gulex (Micraëdes) inconspicuosus, Theo.}

LARVA.-The larva of this mosquito has not yet been identified.

Pupa.-The pupa is rather feebly chitinised; length when extended about $3 \mathrm{~mm}$. Four pelts were examined.

Cephalothorax. The respiratory trumpets (fig. 25, a) are long and narrow, with a broad dark band a little proximal to the middle ; length about $0.57 \mathrm{~mm}$., middle breadth about $77 \mu$; the opening is of moderate size, the ratio of the length of the meatus to the total length of the trumpet being about 1 to $1 \cdot 3$. The setae on the cephalothorax are small and not very highly chitinised. The dorsal setae are rather long tufts of two to four hairs. The postero-thoracic setae are moderately welldeveloped tufts, the inner of about four, the median two, and the external three hairs.

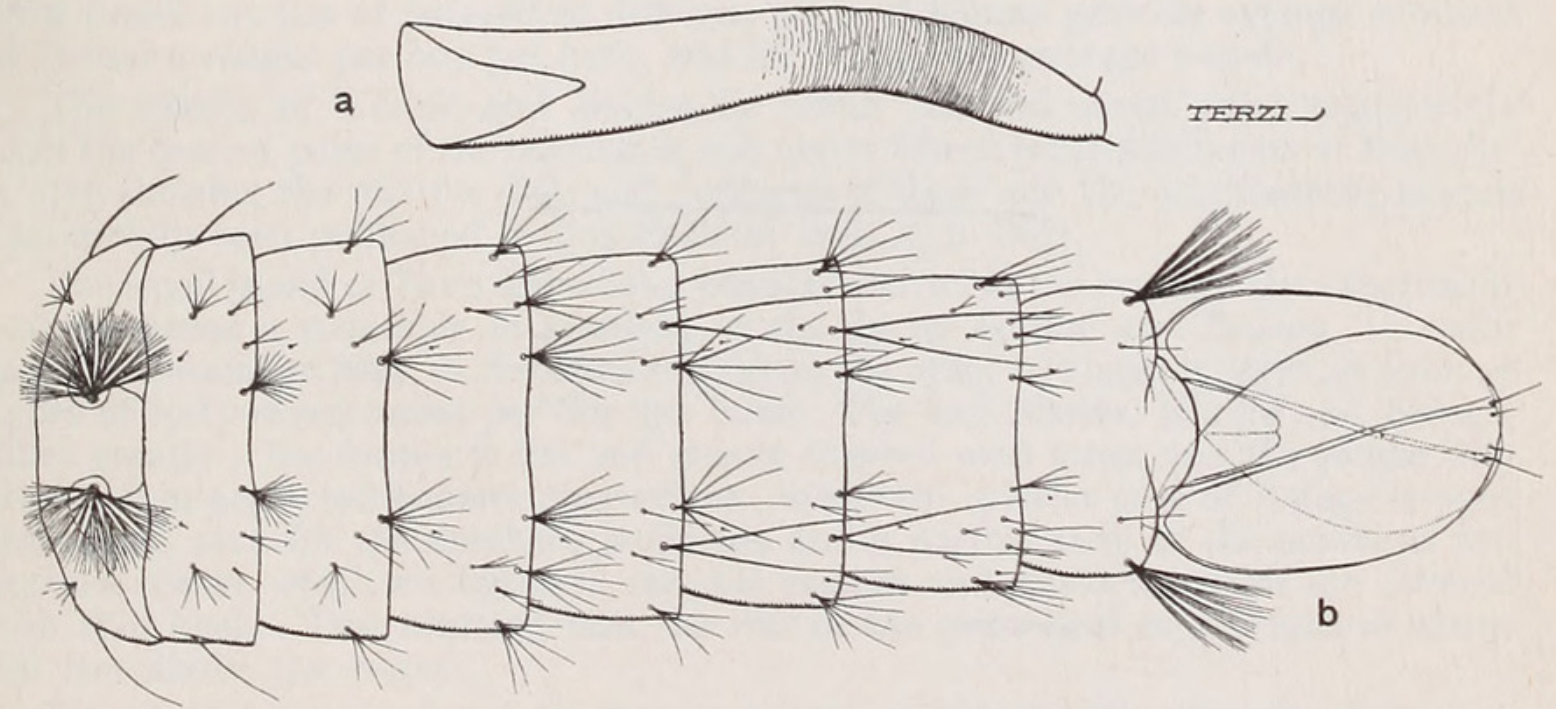

Fig. 25. Pupa of Culex inconspicuosus, Theo. : $a$, trumpet; $b$, dorsal view of abdomen.

Abdomen (fig. 25, b). The paddles are obovate ; length about $0.6 \mathrm{~mm}$., greatest breadth about $0.4 \mathrm{~mm}$. The midrib is moderately well developed, and there is a narrow external buttress which appears to extend about half the length of the paddle. At the distal end of the midrib are two hairs, the one rather long, nearly one-fifth the length of the paddle, and the other quite short (about $30 \mu$ ); these hairs are usually single, occasionally forked. There is no fringe. 
The arrangement of the abdominal setae, except in the case of the following dorsal setae, does not call for special mention. The lateral setae on segments iii to vi are tufts of about five delicate hairs, on segment vii tufts of three or four stout branched setae, and on segment viii rather larger tufts of five or six similar setae. The lateral tufts on segment viii are about two-fifths the length of the paddles. The sublateral setae on segments $\mathrm{v}$ and vi are long double setae reaching further than the posterior margin of the following segment; on segment vii they are single or double, shorter and smaller, not reaching quite across the eighth segment; and on segment iv they are moderate-sized tufts of hairs. The submedian setae on segments iv to vii are tufts of hairs which are largest on the more anterior segments. The dendritic tufts on segment $\mathrm{i}$ are well developed and have about ten primary branches. On the posterior margin of segment ii, on each side of the middle line, are tufts similar to those of Culex; these tufts are delicate, their stems rather narrow, and their branches very fine hairs.

Diagnosis. - The pupa in most respects resembles that of Culex, but apparently may be distinguished by the fact that one of the terminal setae on the paddle is long, nearly a fifth the length of the paddle.

Habitat.-Oblogo, 25.xii.1920, from pools in swampy ground. 


\section{$2 \mathrm{BHL}$ Biodiversity Heritage Library}

Macfie, JW S and Ingram, A. 1923. "The early Stages of West African Mosquitos.-VI." Bulletin of entomological research 13, 409-442. https://doi.org/10.1017/s000748530004551x.

View This Item Online: https://www.biodiversitylibrary.org/item/110744 DOI: https://doi.org/10.1017/s000748530004551x

Permalink: https://www.biodiversitylibrary.org/partpdf/201561

\section{Holding Institution}

Smithsonian Libraries

\section{Sponsored by}

Biodiversity Heritage Library

\section{Copyright \& Reuse}

Copyright Status: Public domain. The BHL considers that this work is no longer under copyright protection.

This document was created from content at the Biodiversity Heritage Library, the world's largest open access digital library for biodiversity literature and archives. Visit BHL at https://www.biodiversitylibrary.org. 